If

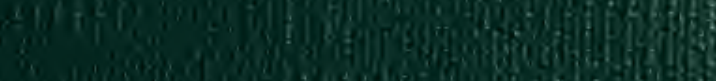

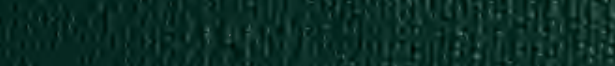
Sho (1) (1)

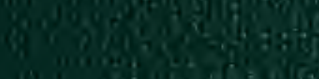

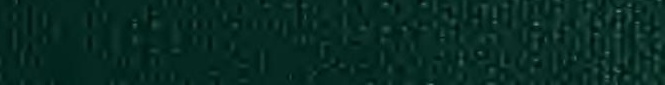

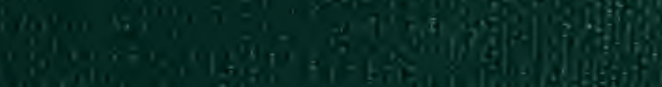
W.

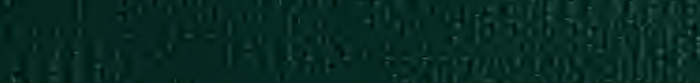

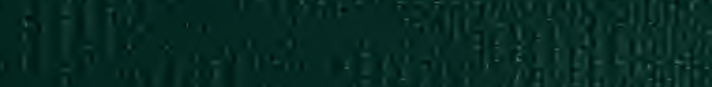

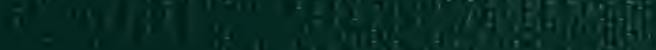

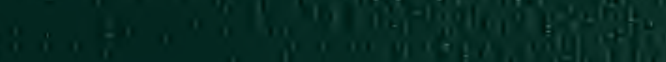
-

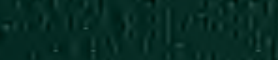

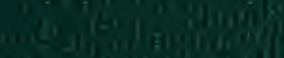
tor

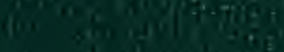

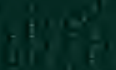

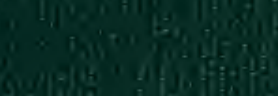
It

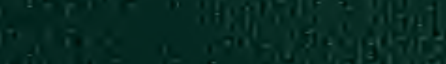

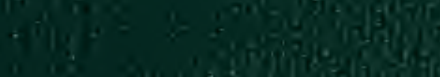
ing

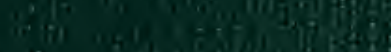





\section{PSELAPHIORUM MONOGRAPHIA}

. CUM SYNONYMIA EXTRICATA

AUCTORE.

CAROLO AUBÉ

Socielatis Entomologice Gallice sodale.

\section{AD LECTORES.}

Etsi nitidissimis coloribus enitent, aut magnitudine quasi gुigantea, et forma ferè barbara, arripiant oculos peregrinarum regionum insecti, non minorem observatorum admirationem nostratûm insectorum fabrica provocat, et natura maximè miranda in minimis nostris opibus externas Entomologixe divitias anteponere vetat. Quod quidem magis ac nagis Entomologis hodiernis confirmatur, quippequi micrographicis laborilous incumbunt, et jamjam notatis novum opus miraculis refertum addit quisque dies; sic gyenus quodcumque sit insectorum, microscopicis dicam speciebus conflatum, suam peculiarem descriptionem et monographiam, ut aiunt, jam possidet.

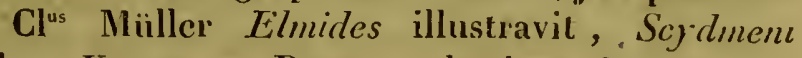
Clor Kunze et Denny solertian fugere non «833.

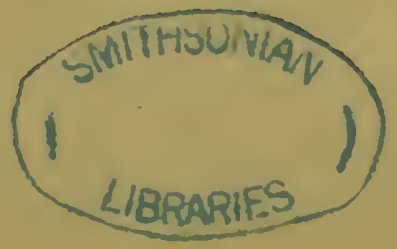


potucrunt, a $\mathrm{Cl}^{\circ} \mathrm{Germar}$ et $\mathrm{Cl}^{\circ} \mathrm{Kirby}$ Apiones fuerunt recensiti, $\mathrm{Cl}^{\text {ns }}$ Illiger Alticarum genus edidit, et Cryptophagi et Scaphidia $\mathrm{Cl}^{\circ}$ Schuppel genus Ptilium tribuerunt. Plures adhuc supersunt clarorum auctorum productiones, quas hic numerare longius et supervacuum est; sed inter eas non tacendae et pratermittendae sunt $\mathrm{Cl}^{\mathrm{i}}$ Reichenbach et $\mathrm{Cl}^{\mathrm{i}}$ Denny Pselaphior um monographia. Rudis antea indigestaque moles, $P$ selaphiorum familia obscura adeò hucusque delituerat, ut nemine, nisi pro sua virili parte, et ad libitum species determinante, in quacumque insectorum collectione Pselaphiorum quisque varium nomen obtineret. Sed corum Entomologorum patientia huncce scientia campum diligenter adeò exaravit, ut vix specilegii quidquam reliquerint. Quorum vestigiis harentes et novan monographiam Pselaphiorum proponentes, corum monumenta eruere aut minoris pretii facere in mentem non venit; elenim quidquid novi de Pselaphiis tenemus, ut supplementum tantummodò éorum laboribus et addimentum publici juris fieri meretur, sed Entomologorum, præsertim nostratûnı, commodo consulentes tenporis et pecunia dispendium, investigationum taedium ct difficultates, lectoribus parcere voluimus; nam in nostris bibliothecis publicis operorum praedictorum alia desunt, rarissinè apud nos catera veneunt, et vix Pactolii auriferi fluctus sufficerent nunc ad 'mendım omnia quaeque acta acade-

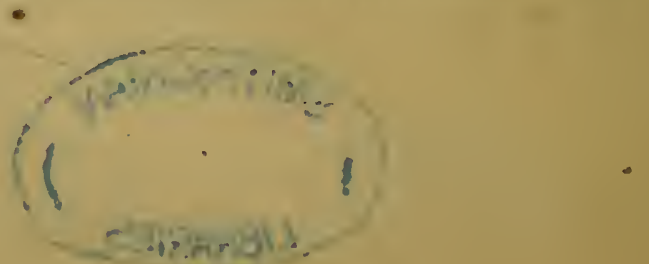


mica, mole sua atlantica, colum jamdudum invadere minantia, in quibus de nostris Psclaphiis quidpiam passim agitur. Igitur rariorum Cl' Reichenbach et $\mathrm{Cl}^{i}$ Denny operum nectareum succum predantes, clarissimorumque Leach, Illifer et catcrorum, in periodicis collectancis, disseminatas gemmas insectantes et in unum coercentes, huncec primogenitum alienis dotibus ornatum Entomologia sectatorum gratia prelo subjicimus. Inıerfectum opus quidem, sed ad manum et utilitate sua forte conmendandum.

Gratum opus insecticolis et optatum valdè, sed arduum tentavimus, nostris conatibus lectores indulgeant.

Sexto die nonarum octobris scripsimus Parisiis Anno Cluristi M. DCCC. XXXIII. 


\section{PROEMIUM.}

In minimis insectorum, elytris abdomen in parte tantun tegentibus, adnumerandi suut Pselaphii, intimam adeò cum Staphylinis affinitatem proferentes, ut alii ab aliis in systemate an distinguendi sint dubitemus. Etenim non solum figura et habitu conveniunt, sed etiam Staphylinorum mores omninò referunt, et quod præcipuum nobis videturanimalibus substantiis pari modo vescuntur; nam, ut in cæteris generibus insectorum carnivorum, pedes ad cursum quam maximè idoneos, mandibulasque longas adnodum et acutas præbent et naturæ indagatio non secus ac analogia rem ad evidentiam usquè facit manifestam; quüm Clus Skimshire Anglorum en tomologus Euplectum sanguineum tenuissimos Acaros incredibili aviditate vorantem observasse refert.

Intimum Pselaphiorum vivendi genus adhuc penè desideratur: per diem in latebras suas sese recipiunt, speculatorum oculos fallentes, nec nisi appropinquante nocte, solummodo propter venationem et generationem vagantur. Ad seram igitur eorum disquisitionem incipere decet; quæquidem solis ad occasum et coelo sereno, in pratis floribundis aut per sylvas umbrosas, lenteario rete gramineas herbas percutiendo instituenda est; quædam Pselaphiorum genera alias petenda sunt; Clavigeri et Batrisi formicarum cuniculos inter quæruntur. $\mathrm{Cl}^{\mathrm{i}}$ Chevrolat et Lucas sicut et nos in ligno carioso, vel ad truncorum radices jam formiculis fulvis occupatas sub hypnis detexerunt Batrisos; lignum putrefactmm humore imbutum plantarumque detritus Brthinis placent : et revera sub arborum jampridem mortuorum corticibus in lımido stantibus Byihinum Curtisii præsertim reperire juvat, et in fimo ad culturam cucumidis melonis preparato sese delectatur Euplectus Kirbii.

Vix nullum inter mares et feminas in plerisque Pscla- 
phiorum gencribus interest discrinen, quod saltem sic habere contendimus, qua de re cum Anglixe Entomologis haud parum dissidentes: hi enim in Bythiniorum, exempli gratia, et Arcopagorim generilsus inter utrunque sexın maximan differentian proponmt, mares esse eos Bythinos quorum antemarum articulus secundus in angulum interne evadit, lemineos contra Bythinos ommes eodem articulo splierico reputantes. Idemque pro feminis Arcopagi bulbiferi lıabent cos quorum articulus primus cylindriciformam adipiscatur, dum mares esse quorum articulus idem intus bisinuatus est opinantur. Talibus sentientibus vix acquiescere docet nature accuratior observatio. Etenim, eodem die et in eodem fimo melonifero, circa quadraginta Bythinos Curtisii omnes inter se ad unguem revera simillimos rejerire nobis invenit, et pro maximè mirandam sane rem teneri, unius tantum sexus tot exemplaria in uno domicilio congregata deberemus. Nusquam unum solumnodo Bythinum secundo antennarum articulo spherico, cxteris characteribus ad hanc speciem conferendum invenimus, et rursiun per multos Bythinos Securigeros colligentes ad ultimum usque, ommes articulum secundum antennarmm securiformen prebuerunt; addemus Bythinos omnes articulum secundum spharicum gerentes qui nobis examinandi pervenerunt seu Bythino glabricolli congruere, seu palporum forma aliis specicbus referendos esse. Quacque tamen ad naturam omnino et mathematica, ut ita dicam, ratione, non probata esse fatemur, quum organorum genitalium anatomica disquisitione non freti eos ad generandun copulantes non vidimus, et coïtum soli Euplecti Kirbii, in quo inter marem et leminam nulla prodit differentia, nobis hucusque considerandi fucrit datum; sed ipse Clus Leach exemplum Kunzece nigricipitis Pselaphiorum generis, in connubio conjuncta in quo genere maris et femina antennarum characteres similes reperiuntur, annotavit. Et ideò quousque ean differentiam inter Bythinos ob- 
servatam ad sexûs notas referendam esse non probatun fuerit, inductionis auspicio antennarum varietatem spccierum clraracteres esse in Bythinis ratum habebimus.

Pselaphiorum historiam explanantibus, in generum distributione, formam exteriorem in genere, præsertinque palporum maxillarium structuram, præcæteris inditiis liabuimus; oris intimarum partium dispositionem habitumque relinquentes, non eo quod negligendum certè, hoc examen, quoties enim potuimus, toties horumce oris organorum delineationem, ad naturam summa diligentia absolutam dedimus, sed quod difficillimum nobis videtur. Omni ope atque opera nitentes palporum labiorum articulos numerare tentavinus, in vanum luctati sumus. Attameu hic ut in Stapliylinis et forsan in omnibus Coleopterorum generibus, articulos tres reperire conceditur.Quod ad palpos maxillares attinet, quatuor articulis instructi in Pselaphiiis inveniuntur ; quorum primus minimus adeò apparet ut Entomologiæ quidam clari scriptores eum abesse omninó sensuerunt. Pselaphum genus palpos maxillares articulos quinque primo as pectu mentientes exhibet, et Clus Denny alioquin nature solertissimus indagator in Pselaphiis rem ita se habere putat; quod miramus ! etenim ut notum est in cateris ColcopteroJum generibus hucusque cognitis nullum palpibus maxillaribus quinque partitis adest specimen, sed propius hace organa intuentibus quatuor tantum modo ut in ejusdem ordinis cateris animalibus occurrunt articuli. Quorum quiden secundus circa mediam longitudinem quamdan, sed non articularem, sed immobilem, erroris unde predicti Deuny causa, structuram refert. Hic loquendi finem facianus. ...... Inum loquimur fugerit invida Etas.... 


\section{NOMINA AUCTORUM,}

\section{Cum abbreviationum explicatione.}

Aut.-Serv. et Lcpel. de St.-Farg. Audinet-Serville et I.cpelleticr de Saint-Fargeau, Encyclopédic méth., t. 10. Paris, 1825 .

Beck Beil. Beitrage sur Baierschen Insecten Fauna, et von L. Beck Ausburg, 1817 .

Curtis Brit. Entom. British entomology by J. Curtis. London.

Dalm. om Ins. On Insekter inneslutne i copal af Dalnan. Stockolnı, 182.6, r rol. in-4.

Dej. Cat. Catalogue de la collection de coléoptères de $M$. le baron Dejean. Paris, $182 r$, 1 vol. in-S.

Denny M. P. Monograplia Pselaphidorumet scydmenidarum Britannix. By H. Denny. Norwich, 1825, 1 vol. in-8.

Fab. Syst. Elcuth. Systema Elentlieratorum a Joh. Christ. Fabricio. Kilix, 1801 , a vol. in-8.

Gory. Mag. de Zool. de Guér. Grory, dans le magasin de Zoologie de Guérin. Paris.

G.ll. Ins. Suecc. Insecta Sueccia descripta a Leonardo Gyllenhal. Scaris. Pars 1, 1808 , pars 2, 1810 , pars 3, 1813, pars $4,1827,1$ tom. in-8.

Herbst. C. Natursystem aller bekaunten in und auslandischen insecten, etc., von. C. G. Jablonsky, und forgelgesetzt von J. F. W. Herbst. Berlin, I 789 , 40 vol. in 8 . Illig. Kaf. Preus. Verzeichniss der Kâfer Preussens entsvorfen von $\mathbf{J}$. Gottleib Kugelaun, augean beitet von J. K. W. Illiger, etc., etc. IIalle, 1798 , in-8.

Latreil. Gen. Crust. et Insect. P. A. Latreille, Genera crus- 
taceorum et insectorum secundum ordinem naturalest in familias disposita, iconibus, exemplisque plurimis explicata. Parisiis et Argentorati, 1809,4 vol. in-8.

Latreille, Reg.anim. Le règne animal, distribué d'après son organisation pour servir de base à l'histoire naturelle des. animaux, etc., par M. le baron Cuvier. Paris, 1829,5 vol. in-8. Le quatrième et le cinquième contenant les Crustacés , les Arachnides et les Insectes, par M. Latreille. Leach. E. E. In Edinburgh Encyclopedia. Edinburgh, 18 r 0 , etc., in- 4 .

Leach. Z. J. The Zoological Journal. London, in-8.

Leach. Z. M. The Zoological Miscellany, or descriptions of new, rare, or highly interestinganimals. By W. E. Leach. London, 1814,3 vol. in-8.

Linn. Syst. nat. Caroli Linnæi systema naturæ per regna tria. Vendobonæ, 1767,3 vol. in-8.

Linn. Faun. Suecc. Caroli Linnæi fauna sueccia. Stockholmix, $176_{1}$, in-8.

Linn. Ent. Caroli Linnæi Entomologia faunæ suecciæ descriptionibus aucta. Lugduni, 1789,4 in-vol. 8.

Marsham. Entomologia britannia sistens insecta Britannix indigena secundum methodum linnæanam disposita, auctore T. Marsham, t. I, Coleoptera. Londini, 1802 , in-8.

Muller ( $P . W . J$.$) In magazin Entomologie von E. F.$ Germar, Halle, $1813-181$ 7-1818-1821, in-8.

Oliv. Ent. Entomologie ou Histoire Naturelle des Insectes, avec des caractères génériques et spécifiques, etc., par M. Olivier. Paris; 789,6 vol. in-4.

Panz. F. I. G. Fauna insectorum Germania initia. Auctore Dr. G. W. F. Panzer. Numberg, 1789 ; etc., in-12.

Panz. F. I. E. Fauna insectorum Europæ auct. Dr. G. W. F. Panzer. Cura Gcrmar, Ialle. 
Pajk. Faun. suecc. G. Paykul Fauna Sueccia. Insecta. Upsalix, $179^{8}$, in-8.

Preysler Ins. Boh. Verzeichniss Bohmischer inseckten. Von

J. D. Preysler. Prague, $179^{\circ}$, in-4.

Reich. M. P. Monographia Pselaphorum. Auct. H. F. L. Reichenbach. Lipsiæ, 1816, I vol. in-8.

Samou. The entomologist's useful compendium, or an introduction to the knowledge of british insects, etc. By G. Samouelle. London, 1819 , in-8.

Schrank. Fau. Boic. P. Schrank Fauna Boica. Nurnberg, $179^{8}$, in-8.

Sturm. Catal. mein. Catalog meiner Insecten-Sammlung.

Van Jacob Sturm. Nurnberg, ${ }_{1} \$_{2} 6,1$ vol. in-8. 


\section{PSELAPHII.}

Pselaphii, Latr. Gen. Crust. et Ins., t. 3, p. 76 .

Psélaphiens, Latr. Reg. anim. de Cuv. , t. 4, p. 16.7.

Pselaphidea, Leach., Zoolog. Miscell., t. 3, p. 80.

Pselaphide, Denny. Mon. Ps. et Scydm., pag. 1.

Pselaphi, Reich. Mon. Ps., p. 17.

Oculi prominuli, in Clavigero nulli.

Palpi qualuor inæquales, anticis majoriljus 4-articulatis, posticis bi-arliculatis.

Labrum corneum, truncalum vel emarginatum.

Labium corneum, cordatum.

Ligula minima, membranacea atrinque appenılice mandibıliformi membranaceo armata.

Manclibulce corneæ arcuatæ 3-6-8-dentatæ, dente prinı majore (inermes tantium in Clavigero).

Maxilla membranaceæ bifidæ lacinia anteriore majore.

Anlenne 1-6-I1 a ticulatæ.

Thorax aut cordatus aut cylindraceo-elongatus.

Elytra apice truncaia.

Ala ab ely tris tectæ.

Scutellum vix perspicuum.

Abdomen latum obtusun.

Pedes elongati; Femoribus clavatis; Tibiis arcuatis; Tarsis Э-articulatis, primo articulo minimo, secundo elongato apice vix dilatato, tertio filiformi ungue simplici aut duplici armalo.

Metamorphosis ignota.

Habitatio. Alii in pratis et sylvis, die sub lapirlibus et hypnis latentes et versus vesperam celeriter in graminibus curreutes, alii in formicetis, alii sub arborum cortice et in ligno putrido.

Victus. Insecta exigua devorant. 


\section{SYNOPSIS GENERUM}

1 Sectio. Antchnis undecim articulatis.

1 Divisio. Tarsis pidactyt.is.

A. Dactylis inaquahibus.

1 Metopias.

B. Dactylis aqualibus.

Palporum tribus articulis primis obconicis.

Thorace fere spherico. . . . . . 2 'yrus.

Palporum secundo articulo spherico, maximo. Antennis monilifornibus. . 3 Chcnnium.

Palpor!me tribus articulis ultimis extus apophysa setacea armatis. . . . . 4 Clenistes.

2 Divisio. Tansis movomactilis.

Corpus leviter elongatum, ely-lra et aldomen depressiuscula. Ultimo palporume articulo maxime elongato clavato. 5 Iseliphlus

Corpus curtum parum convexum. Ultimo palprorum articulo conico leviter extus dilatato. Thorax cordatus tribus foveolis impressus.

(i) Bryaxis.

Corpus curtum convexum ultimo palporume articulo intus maxime dilatato securiformi. Thorax fere angulatus nitidus alssque impressionibus. . . . 7. Trihus.

Corpus valde convexum ultimo palportur articulo intus maxime dilatato sccuri- 
formi. Thorax cordatus, lineola arcuata posticè ad basin impressus. . Corpus elongatum cylindraceum. Ultimo palporum articulo conico intus leviter dilatato. Thorax ovatus sulco transverso posticè impressus. Antennarım ultimo articulo maximo. : . . . . 9 Trimium.

Corpus elongatum, cylindraceum. An-. tenna in fossula laterali insertæ. Thorax tribus sulcis longitudinalibus impressus. . . . . . . . . Io Batrisus.

Corpus elongatum, depressum. Ultimo palporum articulo conico. Thorax sæpe cruciatim impressus. . . . . . I I Euplectus.

2 Sectio. Antennis sex-articulatis.

12 Claviger.

3 SEctio. Antennis uni-articulatis.

13 Articerus. 
I Sectro. Antennis undecim-nrticulatis.

\section{Divisio. Tarsis didactylis.}

A. Dactylis inæqualibus.

\section{Genus. METOPIAS.}

Metopias, Gory.

Caput trigonum; frons antice, anguste, valde producta; anıcnnce geniculatæ, articulo primo maximo; palpi maxillares elongati, articulo primo miuimo, secundo et tertio majoribus cylindraceis, ultimo maximo intus dilatato; Jabiales brevissimi cylindrici. Thonrax cordatus. Elytra li-striata. Abdomen obtusum, marginibus leviter reflexis. Pedes elongati; femorjbus parum clavatis; tibiis fere rectis; larsis elongatis, unguiculis duobus inæqualibus armatis, unguiculo interno longiore.

\section{Metopias curculionoides.}

Metopias curculionoides, Gory. Mağ. de Zool. de Gućr. Cl. 9, pl. 42 .

\section{Tab. 79. Fig. 1.}

Elongatus convexus rufus pube dense vestitus, antennis maximis. Caput trigonum, convexum, rufo velutium, antice, anguste, valde productum, postice latum, in vertice duabus impressionibus obsoletissimis notatum; oculi minimi nigri; palpi maxillares capitis longitudine, labiales minimi ; antennce corporis longitudine, geniculatx, $1^{\circ}$ articulo maximo cylindraceo, 2-7 gradatim minoribus obconico-cylindraceis, 8-9 ovatis ninoribus, 10 lenticulari, $\mathbf{1}$. conico. Thorax velutinus, cordatus, convexus, capite latior, sulco medio impressus. Elytra antice thoracis latitu- 
dine, postice non nilil ampliata et fere recte truncata, in humero plicato-striata et ad suturam uni-striata, densè velutina. Abdomen obtusum, marginibus parum elevatís. Pedes pubescentes, femoribus leviter incrassatis ; tibiis ferc rectis; tarsis elongatis articulo $1^{\circ}$ minimo, 2-3 longioribus xqualilus.

Bis lineam æquat.

In insula Cayenne dominus Lacordaire legit.

Ex museo domini Gory qui ad descriptionem bencrole communicavit.

\section{B. Dactylis æqualibus.}

\section{Genus. CHENNiUn.}

Chennium, Latr. Aud-Servil et Lep. de Saint-Farg.

Caput trigonum, anterius attenuatum, in utroque latere tuberculo acuto armatum ; palpi maxillares breviores, $\mathrm{r}^{\circ}$ articulo minimo spherico, $2^{\circ}$ elongato clavato, 3 maximo spherico, ultimo præcedente minore conico. Antennce superfoliato-moniliformes. Thorax conico cylindraceus. Elytra bi-striata'. $A b$ domen obtusum ; marginibus leviter reflexis. Pedes curti ; $f e-$ moribus compressis in medio dilatatis; tibiis arcuatis; tarsis bi-dactylis.

\section{Cinennidm bituberculatum.}

Chennium bituberculalum, Lat. Gen. Crust. et Ins. t. 3 , p. 77 .

- Aud. Serv. et Lep. de St-Farg. Ency. M. t. ro, p. 22.0.

$$
\text { Tab. 'j9. Fig. } 2 .
$$

Elongatulum convexum castaneo-piceum elytris dilutioribus. Caput rugosum, trigonum, anterius antennatum, posterius rotundatum; fronte in medio impressa, canaliculata unde antice caput bifidum apparet, tuberculum 
minimum pyramidale in ntroque latere sul, antemnis videtur; oculi parum promimuli; antemna moniliformes pube tenussima tecta, decem primis articulis xqualibus, lenticulo-sulgglolosis, ultimo paulo majore ovato; palpi maxillares capite multo breviores. Thorax ruyosus conicocylindracens, antice capite angustior et versus lasiu supra leviter foveolatus. Ely $/ r a$ antice thorace frarum latiora, dein non niliil ampliata, fere recte truncata. Abdomen oh. tusum, marginilus reflexis. Pedes curti; femoribus counpressis intus dilatatis; tibiis arcuatis; tarsis brevibus articulo $1^{\circ}$ minimo.

Jineam paulo excedit.

In Gallia australi dom. Iatreille unicum individumm legit.

Ex museo dom. com. Dejean qui benerole communicavit.

\section{Genus. TYRUS.}

Psclaphus, Reich. Gyll. Payk.

Stapliylinus, Linué. Fabr.

Caput trigonum versus os angustatum; fronti in duobus tulecrulis sulco divisa; oculi prominuli; palpi maxillares capitis longitudine, tribus primis articulis obconicis, ultimo conicoacuminato; antennce diniclii corporis longitudine, extrorsum crassiores. Thorax spherico-ovatus. Ely-lra bi-striata. Pedes clongati; femoriluus crassatis, tibiis arcuatis, tarsis tri-articulatis bi unjuiculatis. 


\section{i. Tyrus mucronatus.}

Pselaphus mucronatus, Panz. Faun. Germ. 89, fig 11.

- _ - _ - Gyll. Ins. suecc. 4; 231,9 .

___ insignis, Reich. M. P. 6o, 16.

-__- sanguineus, Payk. Faun. suecc. 3, 363, I. Staphylinus sanguineus, Limné, syst. nat. 2, 685, 19. - - - Faun. suecc. 853.

\section{-_-_- Entom. t. 1, pag. 4 I 6 .}

_-crassicornis? Fab. syst. eleut. 2, 601, 64.

\section{Tab. 79. Fig. 3.}

Elongatulum, convexum, capite, thorace abdomineque nigris, elytris rufo-lerrugineis. Caput trigonum, rersus os angustatum, in vertice duabus foveolis rotundatis impressun ; oculi nigri, prominuli granulati ; palpi maxillares capitis longitudine, testacei, articulis tribus primis obconicis, gradatim majoribus, ultimo conico acuminito; antennce ferrugineæ, articulo $1^{\circ}$ cylindraceo, $2^{\circ}$ majore ovato et crasso, 3-8 minoribus æqualibus, 9-1 o gradatim majoribus, apice subtruncatis, ultimo maximo ovato. Thorax capite paulò latior, longior, sphœrico-ovatus, pube tenuissima tectus et postice duabus lateralibus foveolis lineola arcuata confluentibus notatus. $E l_{3}$ tra rufo-ferruginea bistriata, stria suturali integra, dorsali postice evanescente; humeris elevatis. Abdomen nigrum obtusum, marginibus reflexis. Pedes longiusculi rufescentes, coxis primis et secundis spina parva et longiore armatis, frmoribus claratis primis dente minima intus instructis, tibiis arcuatis, tarsis pallidioribus, didactylis.

Lineam paulò excedit. 
Habitat in Suecia et Germania, sub arborum cortice, muscis et lapidibus.

\section{Genus. CTENISTES.}

Ctenistes, Reich. Aud Serv. et Lep. de Saint-Farg.

Dionyx, Aud. Serv. et Lep. de Saint-Farg.

Caput antice productum, os angustatum bi-lobum; oculi prominuli granulati; palpi maxillares capite longiores, I articulo uninimo spherico, $2^{\circ}$ clavato arcuato, $5-4$ cuneiformibus transversim impositis, his tribus ultimis apophysa setacea extus armatis; antennce dimidio corpore longiores, extrorsun gradatim crassiores. Thurax conico-cylindraceus. Elytra bi-striata. Abdomen latun, obtusum, marginibus reflexis. Pedes longius culi, femoribus incrassatis, tibiis arcuatis, tarsis bi-unguiculatis.

\section{Cienistes palpalis.}

Ctenistes palpalis, Reich. M. P. 76, tab. r, fig. A.

—_- - Latreil., Règ. anim., t. 5, pag. 165.

méth., t. Io, p. 220.

Tab. 79. fig. I.

Testaceo-rufescens, elongatus, parum convexus, pilis albis raris tectus. Caput trigonum antice productum, bi-lobum, in rertice duabus foveolis obsoletis impressum ; oculi nigri; palpi capite longiores, articulis tribus ultimis seta longa armatis; antennee dimidii corporis longitudine I articulo cylindraceo, 2 spherico sequente majore et precedente minore, 3- 7 obconicis gradatim paulo majoribus, 8 etiam obconico sed minore, 9- 10 obconico-sphericis majoribus, cum ultimo elongato-ovato clavam efformantibus. Thorax co1833. 
nico-cylindraceus capite longior et antice angustior, lateribus, basi et foveola media dense albo-pilosis. Elytra ad basin thorace vix latiora, postice dilatata, fere recte truncata, margine postico dense albo-piloso, striis duabus, suturali integra, dorsali postice abbreviata. Abdomen latum, marginibus reflexis, segmento primo ab elytris non tecto, ad marginem posticum dense piloso. Pedes graciles pallidi, tarsis pallidiorius.

Lineam æequat.

Habitat sub hypnis in Germania rarissime.

\section{Ctenistes Dejeanil.}

Dionyx Dejeanii, Aud. Serv. et Lepel. de St-Farg. Encyc. méth., t. 1o, p. 220 '.

Tab. 79. Fig. 2 .

Capite, palpis, thorace, elytris, abdomine et pedibus præcedenti omnino similis, antennis aliter constructis tantum distinctus : articulo r cylindraceo, 2 spherico sequente majore et præcedente minore, 3- 7 æqualibus minimis, lenticulari-sphericis, coarctatis, 8-ro cylindraceo-conicis, elongatis ( 9 breviore), 1 I elongato-ovato. An precedentis mas?

Lineam æquat.

In Gallia meridionadi rarissime. Dom. Com. Dejean, in præfectura Atacis, unicum individuum volantem versus vesperam cepit, et hunc ad descriptionem benevole communicavit.

1 Unico individuo hujus speciei palpis latentibus in museo Dom. Com. Dejean visu, Audinot, Serville et Lepelletier de St-Fargeau genus Dionyx coustituerunt. Certe non sic pcceavissent si individuum cum palpis maxillaribus manifestatis in potestate habuissent. Antennarum mirabilis structura in errorem hos entomophilos induxit. 


\section{Genus. PSELAPHUS.}

Pselaphus, auctorum.

Anthicus, Panzer.

Caput antice productum, bi-lobum; oculi prominuli; palpi maxillares longissimi fere antennarum longitudine, articulo I minimo cylindrico, 2 longissimo basi tenue, in tertia parte breviter abrupte angustissimo et apice leviter clavato, $5 \mathrm{ob}-$ conico-minimo, ultimo longissimo amplius clavato; antennce dimidio corpore longiores, gradatim extrorsum crassiores. Thorax elongato-ovatus. Elytra depressiuscula, sub-triangu laria, duabus striis notata, fere recte truncata. Aldomen postice magis dilatatum, marginibus late reflexis. Pedes graciles, femoribus incrassatis, tibiis arcuatis, tarsis monodactylis.

A. Thorace postice linea transversa non impresso.

1. Pselaphus heisei.

Pselaphus Heisei, Herbst. C. 4, p. $109, \mathrm{n}^{\circ}$ 1, pl. 36 , fig. $9, a$.

- - Reich. M. P. 28, f. 2

- - Leach. Z. MI. 3.

- - - Denny M. P. 45, tab. 6, f. 2.

-_ - Latreil. Gen. Crust, et Ins. 3, p. 76. Gyll. Ins. Suec 4, p. 223, n० 1 .

—__ eyrigaster, Beck. Beyt. I 1 , tab. 2, f. 8.

___ gracicollis, Dalh.

Tab. 8o. Fig. I.

Elongatulus, cynnamomeus, rufo-ferrugineus, vel fere piceus. Caput prorectum trigonum ; frons in medio pro- 
funde canaliculata; vertex elevatus, nitidus et utrinque leviter bi-foveolatus; oculi nigri, granulati; palpi corpore pallidiores, pubescentes, articulis primis gracilioribus, ultimo clavato, clava ovato-elongata ; antennce corpore dimidio longiores, $1^{\circ}$ articulo magno, cylindraceo-elongato, $2^{\circ}$ ovato crasso , 3-8 minoribus nodosis, 9-1o iterum majoribus, late obconicis, ultimo magno, ovato, apice extus leviter oblique truncato. Thorax ovatus capite longior, antice et postice attenuatus, in medio ampliatus, nitidissimus, absque impressionibus. Elytra sub-triangularia, depressiuscula, bi-striata, stria suturali integra recta, dorsali etiam integra sed arcuata. Abdomen postice ampliatum, marginibus reflexis, segmento $1^{\circ}$ maximo. Pedes graciles, femoribus parum incrassatis, tibiis arcuatis, tarsis pallidioribus.

Lineam paulo excedit.

Habitat sub muscis et arborum cortice, in locis humidis frequens, in Gallia, Anglia, Suecia, Germania, etiam Parisiis.

\section{Pselaphus herbstil.}

Pselaphus Herbstii, Reich: M. P., pag. 25, fig. I.

\section{Leach. Z. M., 3, 8 7.}

Samou. 179 , tab. 4 , fig. 15.

Denny M. P., 43, tab. 9, fig. I.

Heisei, Herbst. c. 4 , p. 110 , tab. 39, fig. 10.

brevipalpis, Schrank, Faun. Boic. I, 438 .

Tab. So. Fig. 2 .

Elongatulus, testaceo-cynnamomeus. Caput antice productum sulco profundo impressum ; vertice elevato lævi; oculi nigri ; palpi pallidi, clava ovata; antennce dimidio corpore parum longiores, ut in precedente, articulo ultimo parum longiore et graciliore. Thorax fere cylindricus capite 
longior, non latior, antice et postice vix angustatus, absque impressionibus. Elytra sub-triangularia ad basin thorace parum latiora, dein valde ampliata, fere recte truncata, depressiuscula, bi-striata. Abdomen obtusum, inarginibus reflexis. Pedes testacei longiusculi, femoribus tibiis que gracilibus, tarsis dilutioribus.

Lineam paulo excedit.

A precedente, thorace angustiore fere cylindrico tantum differt et antennis pedibusque gracilioribus.

Habitat sub hypuis lapidibus et arborum cortice rarissime; in Anglia et Gelmania.

B. Thorace linea transwersa postice impresso.

3. Pselaphus longicollis.

Pselaphus longicollis, Reich. M. P., 3o, f. 3.

-—- - - Leach. Z. M., 3, S7.

Samou, 1, 35.

-_ - Denny M. P., 46, tals. 10 , fig. I.

——_ Gyll., Ins. suec., t. 4, pag. 224, $n^{\circ} 2$.

Dall.

Anthicus dresdensis. Panzer. F. J. G. $9^{8}$, fig. 1.

Tab. 8o. Fig. 3.

Parum elongatus piceo-rufescens. Caput prorectun, trigonum, in medio profunde sulcatum; vertex elevatus, nitidus, utrinque bi-foveolatus; oculi nigri prominuli; palpi pallidi, clava ovato-clongata, extus magis ampliata; antenne ut in Heisei. Thorax oblongo-ovatus, capite longiol nitidus, tenue pubescens, antice duabus foveolis obliquis, postice linea arcuata punctoque intermedio profunde impressus. Elytra sub-triangुularia, depressiuscula, oblique 
truncata, lineis duabus ex foveolis versus basin prodientihus, notata, suturali integra, dorsali postice abbreviata. $A b$ domen latum, obtusum, marginibus reflexis. Pedes piceo rufescentes, pubescentes, femoribus crassiusculis, tibiis arcuatis, tarsis pallidioribus.

Lineam paulo excedit.

Habitat in pratis depressis, sub muscis, et versus vesperam in graminibus ambulat, rarius ; in Gallia, Anglia, Austria et Saxonia.

4. Pselaphus dresdensis.

Pselaphus dresdensis. Herbst C. 4, pag. 110 , tab. 39, fig. 11. Reich. M. P., 32, fig. 4 .

Leach. M. Z. 3. 87 .

- - - - Samou. 1, 35.

Denny. M. P., 47, tab. 10, fig. 2. Gyll. Ins. suec., t. 4, pag. $225, \mathrm{n}^{\circ} 3$. Heisei. Payk. Faun. Suec., 2, 364, $\mathrm{n}^{\circ} 2$.

Tab. 8o. Fig. 4 .

Minus elongatus, piceo-nigricans. Caput trigonum, antice productum, in fronte profunde canaliculatum ; vertex elevatus nitidus ; oculi nigri prominuli; palpi corpore pallidiores, clava ovato-elongata; antennce ut in Heisei sed graciliores. Thorax oblongo-conicus, capite paulo longior, antice angustior, in medio valde ampliatus et postice leviter angustatus, versus basin linea semi-circulari impressus. Elytra sub-triangularia, depressiuscula, $\cdot \mathrm{ad}$ basin thorace parum latiora et ad apicem valde ampliata, dense ciliata, fere recte truncata, bi-striata, stris integris, suturali recta, dorsali arcuata. Abdomen latum marginibus reflexis. Pedes graciles, testacei pubescentes, femoribus clavatis, tibiis arcuatis, tarsis dilutioribus.

Lincain acquat. 
Habitat sub muscis, locis humentibus, in Gallia, Anglia, Austria, Suecia rarius. Semel Parisiis legi ‘

\section{Genus. BRYAXIS.}

Bryaxis, Knoch, Leach, Samou., Denny, Latreille. Pselaphus, Panz., Illig., Payk., Reich., Gyll. Staphylinus, Linné. Anthicus, Fabricius. Reichenbachia, Leach.

Caput trigonum, tri-foreolatum (tantum in $B$. tomentosa. infoveolatum); oculi prominuli, granulati ; palpi capitis longitudine, crassiusculi, $I^{\circ}$ articulo minimo spherico, $2^{\circ}$ clavato arcuato, $3^{\circ}$ obconico fere spherico, ultimo maximo conico, extus parum ampliato; antennce extrorsum gradatim crassiores, $\mathrm{I}^{\circ}$ alticulo cylindraceo magno, 2 ovato, 3-7 minoribus obconicosubglobosis, 8 minimo globoso , 9-10 gradatim majoribus, lenticulari-obconicis, ultimo conico (antennæ tantum in Bryaxi antennata aliter sunt constructæ). Thorax cordatus tri-foveolatus. Elytra convexa bi-striata. Abdomen latum obtusum, marginibus reflexis. Pedes longiusculi, femoribus validis, clavatis, tibiis arcuatis, tarsis monodactylis.

Nescio an specics in Zoogical journal, t. II, p. 453, a domino Leach descripta sub nomine nigricans sit nova. Descriptionem perbreven hic refero: "Corpore toto nigrescente; antennis, palpis pedibusque pallidioribus," 
A. Thoracis foveolis requalibus, aut media majore.

* Foveolis sulco transverso conjunctis.

I. Bryaxis longicornis.

Bryaxis longicomis, Leach. Z. M., 3, 85 et Z. J., 2, 45 I. Samou., 1, 7 . Denny M. P., 32, tab. 7 , fig. 2.

Tab. 81. Fig. 1.

Convexa parum elongata, nigra, elytris rubris. Caput trigonum, tri-foveolatum, foveola antica majore, duabus minoribus rotundatis in fronte; oculi globosi, nigri; palpi capitis longitudine, ferruginei ; antennæ piceæ, pilosæ, dimidio corpore multo longiores, articulo primo elongato, cylindraceo, 2 ovato crasso , 3-8 minoribus, elongatis, $8 \mathrm{mi}-$ nimo, 9-10 longioribus, gradatim cum undecimo apice acuminato clavam efformantibus. Thorax cordatus, glaberrimus, niger, antice et postice angustatus, lateribus valde ampliatus, foveola media, singulaque paulo anterius in utroque latere, tribus sulco transverso conjunctis, impressus. Elytra ferrugineo-rubra, ad apicem nigro transverse vittata, antice thorace latiora, posterius non nihil dilatata, bi-striata, stria suturali integra, dorsali leviter abbreviata, humeris elevatis. Abdomen latum nigrum, lineis duabus minimis obsoletis divergentibus impressum, tribus primis segmentis fere æqualibus, marginibus reflexis. Pedes ferruginei, tibiis anticis in medio intus unidenticulatis, tarsis rufescentibus.

Lineam paulo excedit.

Habitat in Gallia et Anglia in pratis depressis. Parisiis aliquoties legi, locis Petit Gentilly et Bondy. 
2. Bryaxis singuinea.

Pselaphus sanguineus, Ill. Kaf. Preus., pag. 291.

—_— - —— Reich. M. P., pag. 49, fig. 11.

Anthicus - - Eab. syst. Elenth. 1, pag. 293, un 2.2.

Bryaxis sanguinea, Leach. Z. M. 3-85 et Z. J. 2,45 r.

-_— - - Samou., 1-7.

Denny. M. P. 34, tab. 7 , fig. 3.

Tab. 8r. Fig. 2.

A precedente tantum antennis brevioribus et aliter sculptis distincta. Antennarum articulo primo longiore, cylindraceo , 2 ovato crasso , 3-7 minoribus, obconico-subglobosis, 8 minino, 9-10 gradatim majoribus, truncatis, ultimo conico, acuminato. Tibice anticæ inermes. (An præcedentis femina?)

Lineam paulo excedit.

Habitat in pratis lsumidis, in Gallia, Anglia, Austria. etc. Parisiis haud raro legi locis Petit Gentilly et Bondy.

* Foveolis non sulco transverso conjunctis, coxis anticis INERMIBUS.

3. Bryaxis fossdlata.

Pselaphus fossulatus, Reich. MI. P., p. 54, f. 13.

- Gyll. Ins. Suec. 4, pag. 233, 1010.

dresdensis, Payk, F. S. 2, $365, n^{\circ} 3$.

___ castaneus, Beck. Beyt., pag. I1, fig. 9 .

Bryaxis tripunctata, Kuoch.

-_- fossulata, Leach.Z. M. 3, 86 .

-— - Samou., 1, 7 .

—_ —_ Denny, M. P. 37 , tab. 8, fig. 1 .

Tab. 8r. Fig. 3.

Convexa, parum elongata, pubescens, omnino castaneo- 
picea. Caput trigonum, tri-foveolatum ; oculiglobosi, nigri ; palpi pallidi, capitis longitudine ; antenna ferrugineæ, pilosæ, ut in sanguineo sed paulo magis crassæ, articulo ultimo obtuso. Thorax cordatus, in medio valde ampliatus, tribus foveolis æqualibus impressus. Elytra breviora, antice vix basi thoracis latiora, postice valde ampliata, fere recte truncata, bi-striata, stria suturali recta, dorsali arcuata. Abdomen latum obtusum, marginibus anguste reflexis. Primo segmento maximo, duabus lineis minimis divergentibus impresso. Pedes ferruginei, tarsis pallidioribus.

Lineam æquat.

Habitat in pratis humidis ad radices arborum, in vegetabilibus putrescentibus et quisquiliis sat frequens. Commune Parisiis legi.

\section{Bryaxis hematica.}

Pselaphus hamaticus. Reich. M. P. 52. fig. 19. Bryaxis hematica, Leach. Z. M. 3-86.

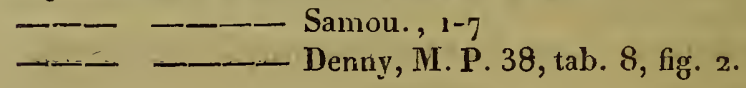

Tab. 82. Fig. 1.

Elongata parum convexa omnino castaneo-cynnamomea. Caput trigonum, tri-foveolatum; oculi globosi, nigri ; palpi pallidi; antennce ut in fossulata sed pallidiores. Thorax cordatus, antice et postice angustatus, non in medio. valde ampliatus, tribus foveolis rotundatis impressus, aliis foveolis irregularibus postice fere conjunctis. Elytra abdomen et pedes ut in fossulata sed colore pallidiore, elytris paulo longioribus et minus ampliatis.

Lineam æquat.

Præcedenti affinis sed colore pallidiore, thorace minus ampliato et foveolis fere conjunctis præcipue distincta. 
Var. $\beta$ Bryaxis perforata. Abdominis segmento primo postice bi-sinuato et foveola profunda utrinque inpresso. 'T. 82, fig. $1, a$.

Var. y Bryaxis sinuata Abdominis segmento primo postice bi-sinuato, imperforato. T. 82 , fig. $1, b$.

Var. $\delta$ Bryaxis bi-denticulata. Abdominis segmento primo postice producto et in medio bi-denticulato. Tab. 82 , fig. $1, c$.

Habitat in pratis humidis et sylvis frequens. Parisiis leģi. Var. $\delta$ communis, V. $\gamma$ rarior et $V$. $\delta$ rarissima.

\section{Bryaxis abdoninalis.}

Tab. 82. Fig. 2 .

Parum convexa rubro-cynnamomea. Caput trigonum tribus foveolis impressum; palpi et antenna ut in $B$. haematica.Thorax cordatus, antice et postice angustatus, trifoveolatus. Elytra antice thorace parum latiora, posterius non nihil dilatata, bi-striata, stria suturali integra, dorsali postice leviter abbreviata. Abdomen latum, primo segmento maximo apice producto, enarginato-bi-dentato, in disco duobus tuberculis elongatis parum elevatis, nitidis, divergentibus, cæteris articulis confuse conjunctis, in medio profunde rotundatim impressis et postice duobus tuberculis prominulis dense pubescentibus notatis. Pedes ut in hamatica.

Lineam æquat.

Statura, color et similitudo hematice, thorace amplius dilatato, foveolis tribus rqualibus non conjunctis et tandem abdomine aliter sculpto distinctus.

Ex museo dom. com. Dejean qui ex America septentrionali accepit et mihi ad descriptionem benevole communicavit. 


\section{Bryaxis depressa.}

Tab. 82. Fig. 3 .

Elongata minus convexa, depressiuscula. Caput trigonum, nigrum, tri-itnpressum ; oculi nigri prominuli ; palpi nigri; antennce piceæ, extrorsum nigricantes, dimidii corporis longitudine. Thorax castaneo-pallidus, depressiusculus, ante medium ampliatus, tribus foveolis æqualiJus impressus. Elytra depressiuscula, cynnamomea, antice thorace parum latiora, non nihil posterius dilatata, apice recte truncata, duabus striis notata, suturali integra, humerali parum abbreviata; humeris elevatis. Abdomen nigropiceum, obtusum, màrginibus reflexis, primo segmento maximo, duabus lineolis minimis divergentibus in disco impresso. Pedes colore corporis dilutiores.

A cæteris tantum corpore depressiusculo distincta.

Dom. de Laporte hanc specienı ex agris Telonis accepit et mihi benevole concessit.

*** Foveolis non sulco transvekso conjunctis, coxis anticis SPINA ACUTA ARMATIS.

\section{Bryaxis lefebvrei.}

Tab. 83. Fig. I.

Convexa, minima, nigro-picea. Caput nigrum, trigonum, tri-impressum; oculi nigri; palpi picei; antenna ut in fossulata. Thorax cordatus, in medio ampliatus, tri-foveolatus. Elytra picea aut ferruginea, antice tlorace parum latiora, postice non valde ampliata, fere parallela, bi-striata. Abdomen nigrum, primo segniento maximo. Pedes graciles, picei; coxis anticis in nonnullis (an maribus?) spina arcuata armatis. 
Hæc species fossulata dimidio minor, el ytris magyis angustatis et coxis anticis spina armatis valde distincta.

Lineam non æequat.

Habitat cum fossulata sed rarior, tamen Parisiis, et præcipue in silva Bondy, circum stagna, versus vesperam pluries legi.

\section{Bryaxis Robrtpennis.}

Tab. 83. Fig. 2.

Elongata, convexa, niģro-picea. Caput trigonum, triimpressum ; oculi nigri ; palpi picei; antennce testacex ut in fossulata. Thorax cordatus, magis convexus, ante medium valde ampliatus, postice magis angustatus, piceoobscurus, non nitidus, tri-foveolatus, foveola media oblon- giuscula, duabus cxteris rotundatis non supra sed in lateribus impressis. Elytra sanguineo-rubra, bi-striata. Abdomen nigro-piceum, primo segmento maximo. Pedes pallidi, longiusculi, coxis anticis in omnibus individuis spina arcuata armatis, tibiis intermediis intus apopliysa breviore ornatis.

Lineam paulo excedit

A cæteris facile distincta thorace postice angustiore et tribus foveolis non in disco impressis.

In Gallia, Austria et Germania, sub lapidibus in pratis depressis rarins. Unicum individnum Parisiis legi.

\section{Bryaxis xanthoptera.}

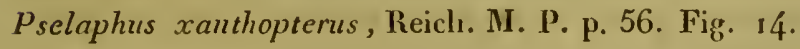

Tab. 83. Fig. 3.

Elongata, convexa, nigra, elytris ferrugineo-rubris. $C a-$ put trigonum, tri-impressum ; oculi nigri; palpi nigri ; an- 
tennce piceæ, ut in fossulata. Thorax nigro-nitidus, cordatus, in medio valde ampliatus, tribus foveolis rotundatis æqualibus impressus. Elytra ferrugineo-rubra, bi-striata. Abdomen nigrum, marginibus reflexis, primo segmento maximo. Pedes picei; coxis anticis in nonnullis individius (an maribus?) spina arcuata armatis et tibïs intermediis apophysa spiniforme ornatis, in feminis coxis mu. ticis et apophysa tibiarum minus elongata et minus acuta.

Lineam æquat.

Coxis anticis non in omnibus individuis spina armatis, apoplıysa tibiarum longiore et tandem thorace in medio ampliato et nitido a præcedente valde distineta.

Habitat in pratis depressis Germaniæ rarius.

B. Thoracis foveolis incequalibus, media minima.

10. Bryaxis Gory.

Tab. 83. Fig. 4 .

Convexa, parum elongata, castanea, abdomine minus obtuso. Caput trigonum", tri-impressum; oculi nigri; palpi pallidiores, capitis longitudine; antennce testaceæ ut in fossulata. Thorax nitidus, cordatus, antice et postice angustatus, valde ante medium dilatatus, tribus foveolis inæqualibus notatus, foveola media minima. Elytris convexis , bi-striatis, stria suturali integra, dorsali brevissima, leviter impressa vix perspicua. Abdomen latum minus quam in præcedentibus obtusum, fere acutum, marginibus reflexis et primis segmentis æqualibus. Pedes ut in fossulata.

Lineam æquat.

Ex nuseo dom. Gory qui ex America æquinoxiali accepit. 
11. Bryaxis impressa.

Pselaphus impressus. Pauz. F. I. G. 89-10.

- - Reich. M. P. 58, fig. 15.

Bryaxis impressa, Leach. E. E., 9-117.

-— - - Samou. 1-7.

Denny. M.P. 36, tab. 7, lig. 4.

Tab. 84. Fig. I.

Convexa, parum elongata, nigra, elytris rubris. Caput trigonum, tri-impressum; oculi nigri, prominuli; palpi testaceo-ferruginei; anlennce picex ut in fossulata. Thorax cordatus, niger, antice et postice angustatus, in medio ampliatus, tribus foveolis inæqualibus impressus, foveola media minima. Elylra convexa ferrugineo-rubra, nitida, ad margines niggrescentia, bi-striata, stria suturali recta, integra dorsali arcuata postice leviter abbreviata. Abdomen nigrum, nitidum, lineis tenuissimis divergentibus inpressuın, primis segmentis æqualibus, marginibus reflexis. Pedes ferruginei, tarsis pallidis.

Vix lineam xquat.

Habitat in pratis humidis ad radices arborum, et versus vesperam in graminibus celeriter ambulat; in Grallia, Anflia, Austria, et etian Parisiis non infrequens.

\section{Bryaxis antennata.}

Tab. 84. Fig. 2 .

Convexa, parum elongata, nigra, elytris rubris. Craput, palpi et oculi omnino ut in impressa; antenna nigro-piceæ intus serratæ, sex primis articulis fermgineis, I articulocy- 
lindraceo, 2 ovato crasso, 3-6 minoribus obconico-globosis, 7-9 cuneiformibus intus dentes efformantibus, 10 quadrato intus compresso, 1 i obconico-elongato. Thorax niger, cordatus, ante medium dilatatus, tribus foveolis impressus, media minima. Elytra omnino ut in impressa. Abdomen nigrum, primo segmento maximo cum duabus lineolis divergentibus, marginibus reflexis. Pedes ferruginè , tarsis pallidioribus.

Lineam æquat.

Præcedente, thorace ante medium dilatato, primo segmento abdominis maximo et tandem antennis aliter sculptis valde distincta.

Habitat cum impressa sed rarior in Gallia. Parisiis pluries legi; a nullo entomophilo Europæ missa.

\section{i3. Bryaxis juncorum.}

Bryaxis juncorum, Leach Z. M. 3-86, et Z. J. 2-452. Samour. 1-7.

-_- Denny. M. P. 40 , tab. 8, fig. 3. Reichenbachia juncorum. Leach. Z. J., t. 2-452.

Tab. 84. Fig. 3.

Convexa, curta, aut testacea, aut cynnamomea, aut tandem fusca. Caput trigonum, tri-impressum ; oculi nigri, prominuli; palpi pallidi ; antennce pallidæ; fere ut in fossulata sed breviores et graciliores. Thorax cordatus, in medio ampliatus, confertissime punctulatns, tribus foveolis inæqualibus notatus, foveola media, minima. Elytra convexa, bi-striata, stria suturali integra recta, dorsali arcuata, leviter postice abbreviata. Abdomen obtusum, marginibus reflexis, primo segmento sequentibus paulo majore. Pedes graciles, testacei, tarsis pallidioribus.

Vix lineam æquat. 
A cæteris colore pallidiore et precipue thorace punctato differt.

Habitat in sylvis, die ad radices arbormm, ct versus vesperam in graminibus ambulat; in Gallia et Anglia. Pluries Parisiis legi in loco Bondy.

14. Bryaxis tomentosa.

Pselaphus tomentosus. Dejean, in Museo.

Tab. \$4. Fig. 4 .

Curta, fusco-cynnamomea, valde pubescens. Caput trigonum, inimpressum, inter oculos sed non in vertice punctatum; oculi, palpi et antennce ut in precedente. Thorax cordatus, antice et postice angustatus, in medio foveola minima vix perspicua et utrinque tantummodo depressionibus obsoletissimis notatus. Ely $t r a$, abdomen et pedes ut in pracedente.

Pube densiore, capite non impresso et forcolis thoracis vix perspicuis a cæeteris distincta.

Ex Museo dom. com. Dejean, ex America septentrionali a domino Leconte missa.

\section{Genus. BYTHINUS.}

Bythinus, Leach, Samou., Denny, Latreille.

Pselaphus, Panz., Payk., Reich., Gyll.

Arcopagus, Leach; Samou., Denny, Latreille.

Bostrichus, Schrank.

Curtus, convexus. Caput trigonum, tri-foveolatum; oculi granulati; palpi maxillares capite longiores, articulo ${ }^{\circ}$ spherico minimo, $2^{\circ}$ clavato, $3^{\circ}$ fere spherico, $4^{\circ}$ securiformi valde intus ampliato, aut globoso-truncato; antennce corporis vix lon. 
gitudine, crassæ, articulo $1^{\circ}$ magno, $2^{\circ}$ etiam magno, aut spherico (Arcopagus, Leach), aut intus magis producto (Bythinus, Leach ), 3-8 sphericis minimis, coarctatis, æqualibus, 9-10 iterum majoribus lenticulari-perfoliatis, 11 maximo, ovato. Thorax sub-globosus, antice et postice angustatus, linea ar:cuata versus basin impressus. Elytra convexa, ad basin bi-plicata et uni-striata, profunde punctata. Abdomen latum, obtusum, marginibus vix visibiliter reflexis. Pedes graciles, femo. ribus incràssatis, tibiis arcuatis, tarsis monodactylis.

A. Antennarum secundo arliculo intus producto.

(Bythinus, Leach.)

1. Bythinus Curtisir.

Bythinus Curtisii. Leach. M. Z., 3, 83.

Sainou. I , 8.

Denny. M. P., 20, tab. 3, fig. I.

Bÿlhinus curtisianus. Leach. Z. J., 2, p. 446 .

Tab. 85. Fig. I.

Piceus, pube lævi tectus. Caput trigonum, tri-foveolatum, foveolis frontalibus minimis, vertice elevato et linea tenuissima impresso; oculi nigri, prominuli ; palpi maxillares capite longiores, rufescentes, articulo ultimo intus securiformi-elongato; antennce crassæ, testacex, pilosæ, articulo $1^{\circ}$ crasso cylindraceo, 2 spherico intus leviter acute producto, 3-8 ininimis globosis, 9-1o lenticulariperfoliatis, ultimo conico-ovato. Thorax convexus, capite latior, antice et postice angustatus, supra versus basin linea arcuata impressus. Elytra inflata, sat profunde punctata, basi bi-plicata, ad suturam uni-striata: Abdomen breve, segmentis æqualibus. Pedes testacei, femoribus incrassatis, tarsis pallidioribus.

Lineam xquat. 
Hahitat pracipue in ligno puttido in Gallia et Anglia. Parisis sat commune in vaporariis hortulanorum inveni.

\section{Bythines I.UNIGER.}

Pselaphus homaticornis. Dejean. Cat. , 133.

\section{Tab. 85. Fig. 2 .}

Piceo-rufus, pube tectus. Caput trigonum, tri-foveolatum, in vertice lineolatum ; oculi prominuli ; palpi maxillares pallidi, articulo ultimo intus valde securiformi-ampliato; antennce breves, crassa, articulo primo cylindraceo, 2 intus angulato lunato, 3-8 minimis globosis, 9.1 perfoliatis, 11 ovato-conico obtuso. Thorax sub-globosus, ante medium ampliatus, versus basin supra linea arcuata impressus. Elytra biءplicáta, profunde punctata et ad suturam uni-striata. Pedes picei, femoribus incrassatis, tarsis pallidioribus.

Linea dimidia vix longior.

Habitat in Gallia et Germania. Unicum individuun in graminibus ambulantem Parisiis legi.

\section{Bythinus Burelli.}

Bythinus Burellii. Denny. M. P. 22, tab. 4, fig. I.

Tab. 85. Fig. 3 .

Piceo-rufus, pube tectus. Caput trigonum, tri-impressum, in vertice breviter lineolatum; oculi nigri; palpi maxillares rufescentes, articulo ultimo intus valde securiformi-ampliato ; antenna breves, crassæ, testacea, articulo $1^{\circ}$ magno cylindraceo, $2^{\circ}$ maximo intus angulato lunato-quadrato , 3-8 minimis globosis, 9-10 lenticulari- 
perfoliatis, ultimo crasso obtuso. Thorax sub-globosus, linea arcuata impressus. Elytra valde convexa, punctata, bi-plicata et uni-striata. Abdomen breve, obtusum. Pedes picei, tarsis pallidioribus.

Linea dimidia vix longior.

Habitat in Gallia et Anglia.

Magnitudo, color, et summa affinitas præcedentis; sed secundo antennarum articulo quadrato-lunato valde distinctus.

4. Brthinus securiger.

Pselaphus securiger. Reich. M. P. 45, 9 . Bylhinus - - Leach. Z. M. 3, 83.

Sainou. I, 8.

Denny. M. P. 21, tab. 3, fig. 2 .

Tab. 85. Fig. 4 .

Áut niger, aut piceus, pube lævi tectus. Capuı trigonum, tri-impressum, in vertice sulco tenuissimo notatum; oculi nigri ; palpi maxillares pallidi, articulo ultimo valde intus dilatato; antennce crassæ, testaceæ, articulo io cylindiaceo, $2^{\circ}$ maximo intus acute securiformi, 3-8 minimis glohosis, 9-10 perfoliatis, ultimo crasso obtuso. Thorax omnino ut in duobus præcedentibus. Elytra convexa punctata bi-plicata et uni-striata. Abdomen obtusum. Pedes crassiusculi picei, tarsis dilutiorihus.

Linea dimidia vix longior.

Habitat in humidis pratis ad radices arborum, in Gallia, Anglia et Germania. Parisiis semel legi. 
5. Brtilinus nodicornis ${ }^{*}$

Tab. 86. Fig. I.

Piceus, pubi lavi tectus. Caput trigonum, tri-foveolasum, vertice elevato in medio linea brevissima impresso; oculi nigri prominuli; palpi rufescentes capite longiores, articulo ultimo elongato intus ampliato; antennce testaceæ crassie, articulo $1^{\circ}$ cylindraceo, $2^{\circ}$ dentiformi intus obtuse producto, 3-8 minimis, 9-1 o lenticulari-perfoliatis, ultimo ovato. Thorax convexus, linea arcuata impressus. Elytra inflata profunde punctata, basi bi-plicata, uni-striata. $A b-$ domen obtusum. Pedes crassiusculi testacei, tarsis pallidioribus.

Ter linea quartam partem aquat.

B. Antennarum $2^{\circ}$ articulo non intus producto (Arcopagus, Leach).

6. Bythinus bULbifer.

Pselaphlus bulbifer. Reich. M. P. 37 , fig. 6. - Gyll. Ins. suec. $4,2.8,11^{\circ} 5$.

- - - - - Knoch.

-_- - - - Dahl.

Bostrichus anomalus. Schrank. Arcopagus bulbifer. Leach. Z. M. 3,84.

-_- - Samon. 1, 5.

- D. Denny. M. 24, tab. 5, lig. I.

Tab. 86. Fig. 2.

Aut niger, aut piceus, pube lari tectus. Caput trigonum, tri-forcolatum, vertice sulco tenuissimo notato;

- Dom. Buquet hujus insecti duos individuos generose mibi concessit sub nominibus noticornis Nuller et lentirornis **; ipse ex Saxonia sic denoniuatos accepit. Priusum nonen servavi 
oculi nigri granulati; palpi maxillares pallidi; articulo ultimo securiformi intus elongato-dilatato ; antenne crassa, articulo $x^{\circ}$ maximo intus bi-sinuato, $2^{\circ}$ magno fere spherico, intus ad apicem leviter angulato, 3-8 minimis globosis, 9-10 perfoliatis, I conico-ovato. Thorax convexus, capite latior, antice et postice angustatus, supra versus basin linea arcuata notatus. Elytra convexa, punctata, biplicata et uni-striata. Abdomen obtusum. Pedes crassiusculi, testacei ; tarsis dilutioribus.

Ter lineæ quartam partem æquat.

Habitat ad radices arborum in locis humidis sat frequens, in Gallia, Italia, Anglia et Germania. Parisiis in loco Petit-Gentilly legi.

\section{Bythinus glabricollis.}

Psclaphus glabricollis. Reich. M. P. 43, fig. 8 .

Arcopagus glabricollis. Leach. Z. M. 3,83 . Gyll. Ins.suec. 4 , pag. 22.9, $\mathrm{n}^{\circ} 7$.

Samou. s, 5.

Denny. M. 28, tab. 5 , fig. 4 .

Tab. 86. Fig. 3.

Aut niger, aut piceus, aut sæpius testaceus, pube lavi tectus. Capul trigonum, tri-impressum, in vertice lineola impressum; oculi nigri, prominuli ; palpi pallidi, articulo ultimo intus ampliato, paulo elongato, apice minus obtuso ; antennce testacex, $1^{\circ}$ articulo cylindraceo, $2^{\circ}$ spherico 3-8 minimis globosis, coarctatis, 9-10 lenticulari-perfoliatis, ultimo conico-ovato. Thorax antice et postice angustatus, paulo ante medium ampliatus, supra ad basin linea arcuata impressus. "Elytra convexa, punctata bi-plicata et ad suturam uni-striata. Abdomen obtusum; pedes pallidi, tarsis pallidioribus.

Ter lineæ quartam partem ærquat. 
Habitat in Gallia, Anglia, Italia et Germania rarius, ad radices arborum. A dom. Ducos semel lectus in loco SaintCloud.

Precedenti affinis, primo antennarum articulo cylindraceo et palporum ultimo magis elongato et minus ampliato valde distinctus.

\section{Bythinus Macropalpus.}

Tab. 36. Fig. 4 .

Picens, aut testaceus, pube tectus. Caput Irigonum, tri-foveolatum, et in vertice leviter lineatum ; oculi nigri, prominuli. Palpi pallidi, articulo ultimo curto, valde intus incrassato; antennce testaceæ, crassæ, $1^{\circ}$ articulo cylindraceo, $2^{\circ}$ spherico, 3-8 minimis globosis, 9-1o lenticulari-perfoliatis, ultimo ovato obtuso. Thorax convexus, paulo ante medium ampliatus, linea arcuata impressus. Elytra inflata, punctata, ad basin bi-plicata, ad suturam uni-striata. Abdomen obtusum. Pedes testacei, tarsis dilutioribus.

Linea dimidia vix Iongior.

Habitat in Gallia rarissime, ad radices arborum sub hypuis tantum semel Parisiis legi.

Summa affinitas Glabricollis; sed statura multo ninore, et palporum articulo nltimo magyis incrassato et obtuso abounde diflert.

\section{Bituinus globulipalpos.}

Tab. 87. Fig. 1.

Piceo-testaceus, pube lavi tectus. Caput trigonum, triimpressum; oculi nigri ; palpi pallidi, ariculo ultimo incrassato, fere spherico, apice truncato; antennce testacex onnino ut in precedente. Thorax cordatus, paulo ante medium ampliatus, supra ad basin lincola arcuata in- 
pressus. Elytra punctata, bi-plicata et versus suturam uni-striata. Abdomen obtusum. Pedes testacei, tarsis pallidioribus.

Linea dimidia vix longior.

Habitat in Gallia. Dom. Ducos Parisiis legit.

10. Bythinus clavicornis.

Pselaphus clavicornis. Panz. F. I. G. 99, $\mathrm{n}^{\circ} 3$. Reich. M. P. 40, f. 7 . Gyll. Ins. suec. $4,229, n^{\circ} 6$.

Arcopagus Leach. M. Z. 3, 84 . Samou. I, 5. Denny. M.'P. 25, tab. 5, fig. 2 .

Tab. 87. Fig. 2.

Castaneo-piceus, elytris obscurioribus, pube lævi tectus. Caput trigonum, tri-impressum et in vertice lineola impressum ; oculi nigri prominuli ; palpi pallidi, articulo ultimo intus ampliato, apice minus obtuso; antennce testaceæ crassiusculæ, $1^{\circ}$ articulo cylindraceo, $2^{\circ}$ spherico, extus apice paulơ angulato, 3-8 minimis globosis, 9-ro lenticulari-perfoliatis, I I conico-ovato.Thorax castaneus, convexus, sub-globosus, paulo ante medium ampliatus, antice lavis, postice ad basin punctis minimis et linea arcuata notatus. Elytra picea, convexa, punctata, bi-plicata, unistriata. Abdomen latum, obtusum. Pedes testacei, femoribus crassiusculis, in nonnullis valde incrassạtis (feminæe Denny) tarsis pallidioribus.

Lineam non æquat.

Habitat in Anglia rarissime. 


\section{Brthines Ciengolati.}

Arcopagus puncticollis. * Curtis. British entomology,

t. $9,11^{\circ} 422$. Tab. 87 . Fig. 3.

Castaneus, puhe tectus. Caput trigonum, punctatum, tribus foveolis notatum et in rertice sulco lævissimo inpressum : oculi nigri; palpi pallidi, articulo ultimo intus ampliato-elongato; antenna testacex, crassæ, articulo $1^{\circ}$ maximo apice intus obtuse producto, $2^{\circ}$ splerico, 3-8 minimis globosis, 9 - o lenticulari-perfoliatis, ultimo ovato. Thorax conrexus, paulo ante medium ampliatus, crebre punctatus et lineola arcuata notatus. El frtra convexa, punctata, ad basin bi-plicata, et ad suturam uni-striata. Abdomen obtusum. Pedes testacei, femoribuis crassiusculis, in nonnullis valde incrassatis, et tibiis intus dente minimo armatis (feminæ Denny, mares Curtis), tarsis pallidioribus.

Ter lineæ quartam parten æquat.

In Italia rarissime.

Precedenti et sequenti affinis; primo, capite et thorace punctatis, secundo, antennarum articulo primo in utroque sexu intus producto, valde distinctus. Certe species peculiaris.

\section{Brthinus puncticollis.}

Arcopagus puncticollis. Denuy. M. P. 26, tab. 5, fig. 3 .

Tab. 87. Fig. 4 .

Castaneus, pube levi tectus. Caput trigonum, punctatum, tri-foveolatum et in vertice lineola impressum ; oculi nigri ; palpi pallidi, articulo ultimo intus dilatato-elongato ; antennce testaceæ, articulo $1^{\circ}$ cylindraceo, $2^{\circ}$ splierico, 3-8 minimis globosis coarctatis, $9^{-10}$ perfoliatis, 11 ovato. Thorax convexus, antice et postice angustatus et ante medium 
ampliatus, punctatus, lineola arcuata ad basin supra impressis. Elytra bi-plicata et uni-striata. Abdomen obtusum. $\boldsymbol{P}$ edes testacei, femoribus crassiusculis et in nonnullis valde incrassatis (feminæ Denny), tarsis dilutioribus.

'Ter lineæ quartain partem æquat.

Habitat in Gallia, Anglia, Italia et Germania, sub hypnis.

Præcedenti valde affinis, antennarum articulo primo cylindraceo tantum distinctus '.

\section{Genus. Trchus.}

Psèlaphus, Reich., Payk., Beck Beit., Gyll.

Tychus, Leach, Samou., Denny.

Curtus, parum convexus. Caput trigonum, infoveolatum ; oculi granulati ; palpi maxillares capite longiores, articulo $\mathrm{I}^{0}$ minimo spherico, 2 clavato, 3 triangulari-elongato , 4 securiformi ; anlennce dimidio corpore paulo longiores, articulo ${ }^{\circ} \mathrm{elon-}$ gato, 2 ovato, 5-8 minimis globosis, coarctatis, quinto in masculis multo majore, 9-10 gradatim majoribus, i I ovato. Thorax fere angulatus, postice et præsertim antice angustatus, absque

- Genus Kunzea, quod dom. Leach in Zoolugical Journal descripsit, non vidi. Nescio an sit. norum genus aut tantum species generis Bythini? Hic descriptionem refero:

Genus Kuxzea. (Leach, Zoo!. Journ., tom. II, pag. 448.)

Corpus breve convexum. Antennæ articulis $1^{\circ}$ et $2^{\circ}$ aliis crassioribus, articulo $x^{\circ}$ elongato cylindracec, interne in $\delta$ et $q$ abrupte dilatato, 2 sub-gglobosiusculo, primo tenuiore, articulis 3-8 æqualibis sub-globosiusculis, 9 crassiore lenticulari, 10 globosiusculo-lenticulari nono majore, il crassiore ovato apice acuminato. Palpi maxillares articulo primo filiforni; a pice gradatim clavato, 2 elongato orato, 3 scutiformi basi angustissimo.

\section{Kunzea nigriceps.}

Corpore toto ferrugineo. Antennis palpis pedibusque pallidioribus, capite nigrescente.

Habitat in Aipibus maritimis in sylvis pinestribus rarissime. Mns. dom. Fabre $\delta$ et $q$ in copulatione capta. 
impressionibus. Elytra convexiuscula, bi-striata. Abdomen la tıun minus obtusum, marginibus reflexis. Pedes longiusculi, tarsis monodactylis.

Hoc genus Bythino vicinum corpore minus convexo, secundo palporum articulo longiore, thorace inimpresso et elytris impunctatis minus inflatis prxcipue distinctum.

\section{Tranus Niger.}

o Pselaplus niger. Payk. F. S. 3, p. 365, no 4 .

_ _- nodicornis. Beck Beit. 12 , tab. 2 , fig. 10.

9 - - ruficornis. Dahl.

- - Essembeck.

o et $q$-niger. Reich. M. 1'. 35. fig. 5 .

-

- Tychus niger. Leasi.Z. M. 3.84, etZ.J.2, $\$ 50$.

_-___- Samou. 1, 42 .

Denny. M. P. 3o, tab. 6, fig. 1 .

Tab. 88. Fig. 1.

Picco-niger, cinerco valde pubescens. Caput trigonum, apice leviter bilidum et in vertice lineola tenuissima impressum; oculi nigri. Palpi testacei, $1^{\circ}$ articulo minimo splierico, $2^{\circ}$ clavato areuato, $3^{\circ}$ triangulari-elongato, intus dilatato, $4^{\circ}$ securiformi obtuso, intus valde ampliato; antenne testacex, pilosæ, dimidio corpore paulo longiores, articulo $x^{\circ}$ cylindraceo magno, $2^{\circ}$ ovato etiam magno, 3-8 minimis globosiusculis coarctatis, quin to in masculis multo majore gुloboso obtruncato, 9-10 gradatim majorilus, obtruncatis, nltimo maximo ovato. 'T'horax convexus, capite longior et latior, antice magis augustatus et in lateribus fert

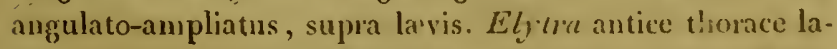
tiora et postice non niliil dilatata, apice fere recte truncata, impunctata, li-striata, stria suturali teuni integra, dorsali valde impressa, postice abbreviata. Abelomen latum, margi- 
uibus reflexis. Pedes graciles ferruginei, tarsis pallidioribus.

Vix lineam æquat.

Habitat in Gallia, Anglia, Sueccia, sub arborum cortice et sub muscis. Parisiis plures legi sed tantum feminam.

\section{Genus. TRIMIUM.}

Pselaphus, Reich., Gyll.

Euplectus, Denny.

Elongato-cylindraceus. Caput trigonum, antice rotundatum, impressum; oculi minuti; palpi capitis longitudine, articulo $1^{\circ}$ spherico, 2 clavato, 3 fere spherico, 4 securiformi ; antennce brevissimæ articulis I- 2 crassis , 3-8 minimis coarctatis, 9-ro lenticulari-perfoliatis, I maximo ovato. Thorax capite vix latior, postice angustatus, foveolis tribus sulco transverso conjunctis impressus. Elytra convexa, vix thorace longiora, impunctata, bi-striata. Abdomen oblongo-ovatum, depressiusculum, marginibus reflexis. Pedes mediocres tarsis monodactylis.

Hoc genus primo aspectu vix Euplecto distinctum, attamen corpore cylindraceo et palpis aliter sculptis certe ab illo separandum.

\section{i. Trimium brevicorne.}

Pselaphus brevicomis. Reich. M. P. 47, fig. 10.

Euplectus - Gyll. Ins. Suec. 4, 230, $\mathrm{u}^{0.8}$

Tab. 88. Fig. 2.

Rufo-testaceus, nitidus glaber. Caput majusculum, trigonum, antice rotundatum, in fronte duabus lineis antice convergentibus impressum; oculi nigri; palpi pallidi, articulo $1_{0}$ minimo spherico, $2^{\circ}$ curto clavato, $3^{\circ}$ fere splierico primo majore $; 4^{\circ}$ securiformi intus ampliato ; antennce testacex vix thoracis mediun attingentes, articulo $!^{\circ}$ maguo 
cylindraceo, $2^{\circ}$ ovato etiam magno, 3 -8 minimis, globosiusculis, coarctatis , 9-ro gradatim majoribus, Ienticulari-perfoliatis, ultimo orato maximo tertiam partem antennæ efformante. Thorax vix capite latior sed multo longior, obovatus, antice et præsertim postice angustatus, supra ad basin tribus foreolis sulco trausverso conjunclis impressus, foveola media majore. Elytra thorace latiora sed vix longiora, bi-striata, stria suturali integra lævi, dorsali abbreviata et valde impressa. Pedes mediocres, femoribus anticis crassioribus, tibiis extus dilatatis, tarsis tenuibus.

Bis tertiam lineæ partem æquat.

Habitat in Gallia, Anglia, Sueccia et Austria sub muscis ad radices arborum. Unicum individuum Parisiis legi.

\section{Io Genus. BATRISUS. -}

Pselaphus, Reich. Bryaxis, Denny.

Corpus cylindraceo-elongatum, convexum. Caput majusculum in vertice tuberculosum, utrinque lateribus elongatoelevatis; palpi maxillares capitis vix longitudine, $I^{\circ}$ articulo minimo spherico, $2^{\circ}$ arcuato clavato, $2^{\circ}$ fere spherico intus leviter angulato, $4^{\circ}$ conico intus parum ampliato; antennce moli niformes fossula laterali orientes. Thorax trapezoïdalis in medio canalicula longitudinali et utrinque singula ante basin cum tribus foveolis conjunctis, his foveolis, media majore, sulco transverso bi-sinuato connexis. Elytra convexa, bi-striata, humeris elevatis. Abclomen elongatum, convexum, postice angustatum, marginibus non reflexis. Pedes graciles, femoribus valde incrassatis, tibiis elongatis, tarsis monorlactylis. 


\section{i. Batrisus formicarius.}

Tab. 89. Fig. r.

Elongato-convexus, cynnamomeus. Caput majusculum, quadratum, granulatum, in vertice tuberculo magno fossula minima in medio impresso et sulco profundo circumducto, marginibus elevatis sulcum ambientibus; oculi nigri granulati ; palpi testacei ; antenna testaceæ pube tectæ, $1^{\circ}$ articulo cylindraceo, 2-8 æqualibus spherico-obconicis , 9-1 0 gradatim majoribus apice intus leviter acute productis, ultimo maximo externe ad apicem et interne ad basin depressiusculo, in nonnullis individuis intus apophysa acuta ad basin armato (an $\sigma^{7}$ ). Thorax trapezoïdalis in medio canaliculo tongitudinali integro et utrinque singula ante basin cum tribus foreolis conjunctis, his foveolis sulco transverso bi-sinuato connexis. Elytra nitida bi-striata, stria suturali integra recta, dorsali abbreviata, humeris valde elevatis. Abdomen elongatum, primo segmento tribus foveolis impresso. Pedes longiusculi, femoribus valde incrassatis.

Habitat in Gallia sub lapidibus et muscis ad radices arborum in societate cum formicis minimis fulvis. Parisis in silris Benoniæe et Fontis-Bellaquei pluries leği.

\section{Batrisus Delaponti.}

Tad. 82. Fig. 9.

Elongato-cylindraceus, convexus, badio-cynnamomeus. Caput majusculum, qradrangulum, granulatum, in vertice tuberculum magnum fossula minima in medio inpressum et sulco profundo circunductum observatur, lateralibus marginibus eleratis antice in tuberculo rotundato terminatis ; palpi pallidi; antennce capitis cum thorace vix longitudine, pube lævi tectæ, articulo $\mathrm{I}^{\circ}$ cylindraceo magno, 
$2^{\circ}$ fere spherico etiam magno, 3-8 æqualibus sphericoobconocis, 9-10 gradatim majoribus obconicis, ultimo orato intus ad apicem depressiusculo. Thorax trapezö̈dalis in medio linea longitudinali et utrinque singula ante basin cum tribus foreolis conjunctis, his foveolis sulco transverso bi-sinuato connexis, inter lineolas leviter utrinque carinatus. Elytra convexa, nitida, bi-striata, stria suturali integra, dorsali abbreviata, humeris elevatis. Abdomen elongatum, primo segumento tribus foveolis impresso. Pedes longiusculi, femoribus incrassatis.

Habitat in Gallia. In ligno pucrido semel Parisiis silva Bononiæ in societate cum formicis minimis fulvis legi.

\section{Batrisus Brollei.}

Tab. 89 Fig. 5.

Elongato cylindraceus, convexus, badio-cynnanomeus. Caput majusculum, trigonum, antice rotundatum et dense longis pilis luteis subornatum, in vertice tuherculum magnum in medio inimpressum, sulco profundo bi-punctato circumductum observatur, marginilus tantum lateralibus elevatis; oculi niggri ; palpi testacei ; antennce testacex pilos $x$, primo articulo cylindraceo-elongato, $2^{\circ}$ ovato unagno, 3-8 minimis æqualibus spherico-obconicis, 9-10 obconicis gradatim majoribus, ultimo ovato brevi extus ad apicem depressiusculo. Thorax, elytra, abdomen et pedes ut in pracedente.

Lineam cum dimidia æquat.

Habitat in Gallia. Dom. Brullé in silva Fontis-Bellaquei unicum individuum invenit in ligno autiquo, et generose mili concessit.

Præcedentis magnitudo et summa affuitås; antennis paulo longioribus et minus coarctatis fere tantum distinctus. 


\section{Batrisus ocelatus.}

Pselaphus oculatus. Dej. Cat. ı 33.

Tab. 89. Fig. 4 .

Elongato-cylindraceus, convexus, badio-cynnamoineus. Caput majusculum, trigonum, granulatum, et sub dense et longe pilosum, in vertice tuberculum magnum in medio infoveolatum sulco profundo bi-punctato circumductum observatur, marginibus lateralibus elevatis et antice ut cornubus rectis obtusis productis ; oculi nigri ; palpi pallidi, articulo ultimo magis quam in precedentibus elongato ; antennce dimidii corporis longitudine, articulo $1^{\circ}$ cylindraceo-elongrato, $2^{0}$ ovato magno, 3-8 æqualibus globoso-obconicis, 9-10 gradatim majoribus, 10 interne acute angulato, ir ovatoelongato extus ad apicem depressiusculo et intus ad basin spina brevissima armato. Thorax, elytra, abdomen et pedes omnino ut in Delaporti, sed tibiæ posticæ spina acuta intus ad apicem sunt arinatæ.

Habitat in Gallia. Unicum individuum a dom. Solier concessum possideo circum Massiliam captum. Parisiis dom. Chevrolat pluries invenit in formiceto.

Præcedenti affinis, sed capite fere cornuto, antennis longioribus gracilioribus et tibiis posticis spina armatis vere distinctus.

\section{Batrisus venustus.}

Pselaplus venustus. Reich. M. P. 65, fig. 18. Bryaxis nigriventris. Denny. M. P. 41, tab. 7, fig. I.

Tab. 9o. Fig. 1.

Elongato-cylindraceus , convexus , badio-cynnamomeus, abdomine nigro. Caput majusculum, trigonum, antice ro- 
tundatum et dense longis pilis luteis subornatum, in vertice tuberculum magnum in medio leviter impressum et sulco profundo bi-punctato circumductum observatur, marginibus, antice minus, postice magis elevatis, sulcum ambientibus; oculi nigri ; palpi testacei. Antenna, thorax, ely-tra, abdomen et pedes omnino ut in pracedente (abdomine nigro et tibiis posticis inermibus).

Lineam cum dimidia æquat.

Irabitat in Gallia, Austria, Italia, Anglia et IIdveti:, sub arborum cortice et in ligno antiquo. Unicum individuum agro Lugdunensi ad radices arboris in liypnis $\mathrm{cmm}$ formicis parvis dom. Iucas mense netohre detexit.

\section{Bathisus albionitios.}

Pselaphlus albionicus. Dej. in museo.

Tab. 90. Fig. 2.

Elongato-cylindraceus, convexus, nirger, elytris castancorestaceis. Caput majusculum, nitidum, in vertice tuberculum parum elevatum in medio fossula vix perspicua impressum et sulco levi circumfluctum observatur, l.oc sulcun postice duabus foveolis rotundatis est terminatum, marginibus anticis et lateralibus parum elevatis sulcum. ambientibus; oculi nigri ; palpi pallidi ut in precelente; antennce testacere dimidii corporis longitudine, articulo $1^{\circ}$ cylindraceo-elongato, $2^{\circ}$ ovato, 3-8 minoribus globósoobconicis, 9-10 gradatim majoribus, ultimo ovato extus ad apicem depressiusculo. Thorax niger, nitidus, trapezoidalis, in medio lineola brevissima et utrinque singula integra ante basin cum tribus foreolis conjunctis, his foveolis sulco transverso bisinuato comnexis. Elytra testacea. Abdomen nigrum, pedes testacei ut in De Laporti.

Lineam cum dimiclia paulo silperat. 
Ex museo dom. Com. Dejean, qui ex America Septentrionali accepit et ad descriptionem communicavit.

$\mathrm{Ab}$ omnibus vere distinctus capite et thorace nitidis, nigris, et linea media thoracis valde antice abbreviata vix perspicua.

\section{Batrists ' lineaticollis.}

$p_{\text {selaphus lineaticollis. Dejean in museo. }}$

Tab. 9o. Fig. 3.

Elongato-cylindraceus, convexus, castaneo-testaceus. Caput quadrangulum, granulatum, in vertice tuberculum magnum in-impressum sulco lævi circumductum observatur, marginibus, antica et lateralibus parum elevatis sulcum ambientibus; palpi ut in albionico; antenna testaceæ, pilosæ, articulo primo cylindraceo-elongato, 2-8 minimis globoso-obconicis, 9 obconico paulo majore, 10 maximo globoso, ultimo ovato-elongato. Thorax, abdomen et pedes ut in De Laporti.

Habitat in America Septentrionali.

Lineam cum dimidia æquat.

Ex museo dom. Com. Dejean, qui ad descriptioneın communicavit.

A cæteris decịno articulo maximo spherico valde distinctus.

8. Batrisus BuQqueti.

Tab. 9o. Fig. 4 .

Elongato-cylindraceus, convexus, castaneo-testaceus, abdomine nigro. Caput majusculum, rotundatum, granulatum, in vertice tuberculo nitido fossula minima in medio impresso et sulco profundo circumducto, marginibus lateralibus elevatis ad apicem fere acute convergentibus, sulcum ambientibus; palpi ut in De Laporti ; antennce..... 
Thorax trapezoidalis, in medio linea longitudinali et utrinque singula ante basin cum tribus foveolis conjunctis , his foveolis sulco transverso bi-sinuato connexis. Llylra ut in De Laporti. Abdomen nigrum, nitidum, elongatum, primo segmento trilsus foveolis impresso. Pedes mediocres, femoriluus incrassatis.

Lineam cum dimidia æquat.

Habitat in Gallia.

Dom. de Laporte unicum individuum sine antenuis in museo possidebat et generose mihi concessit ; tantum lunc vidi.

A cæteris capitis marginibus antice fere acute convergentibus precipue distinctus.

\section{i Genus. EUPLECTUS.}

Euplectus, Kirby, Leach, Samou., Denny.

Pselaphus, Illiger, Payk., Gyll.

Staphylinus, Panz., Marsham.

Anthicus, Fab.

Elongatus, depressus. Caput fere semper impressum; oculi minimi, granulati; palpi maxillares capitis" vix longitudine, articnlo primo sphærico minimo, 2 clavato, 3 fere sphærico primo najore, 4 elongato ovato vix intus ampliato; antennce crasse, breves, vix capitis cum thorace longitudine, primo articulo cylindraceo, 2 ovato crasso, 3-8 minimis globosis, coarctatis , 9-10 majoribus, lenticulari-perfoliatis, 11 maximo, ovato. Thorax depressns, cordatus aut quadrato rotundatus, fere angulatus, supra impressus, et sæe cruciatim. Elylra quadrata, depressa, bi-striata. Abdomen dep:cssum, seymentis æqualibus, narginibus reflexis. Pedes breviusculi, tarsis monodactylis. 
A. Capite impresso.

* In medio vertice yossula minima.

1. Euplectus sulcicollis.

Pselaphus sulcicollis. Reich. M. P. 62, fig. I 7 .

$$
\text { Gyll. Ins. suec. } 234 \text {, no } 41 \text {. }
$$

Dresdensis. Illiger. Kaf. Preuss. $\mathrm{I}$, pag. $290, \mathrm{n}^{\circ}$, Payk. F. S. 2, 365.

Anthicus - _- Fab. Syst. Eleuth. 1, paş. $29^{3}, n^{\circ}{ }_{2} 3$. Bryaxis sulcicollis. Curtis. Brit. Entom. tom. $2, \mathrm{n}^{\circ} 3 \mathrm{3}$.

Tab. $9^{1}$. Fig. I.

Elongatus, depressus, cynnamomeus, valde pubescens. Caput trigonum, angulis obtusis, depressum, duabus in fronte fossulis convergentibus antice late conjunctis, postice in aliis fossulis rotundatis terminatis, vertice elevato, nitido, in disco foveola tenuissina impresso; oculi nigri; palpi maxillares testacei; antenna testacee capitis cum thorace longitudine, pilose, articulo $1^{\circ}$ cylindraceo, $2^{\circ}$ ovato, $\mathrm{s} \approx \mathrm{x}$ sequentibus minimis globosis coarctatis, majoribus, 9-10 iterum majoribus, distantibus, lenticulari-perfoliatis, ultimo maximo parum acuminato. Thorax capite longior vix latior, cordatus, antice et postice angustatus, ante medium dilatatus, ad basin tribus foveolis, media maxima triangularia, sulco transverso conjunctis et in medio linea longitudinali impressus. Elytra thorace Iatiora, bi-striata, stria suturali integra dorsali brevissima, fere recte truncata et ad angulos externos pro abdominis marginibus reflexis excisa. Abdomen latum, depressum, elytrorum longitudine. Pedes rufescentes, femoribus crassiusculis, libiis compressis arcuatis, tarsis pallidioribus.

Lineam cun dimidia equat aut superat. Habitat in Gallia, Anglia, Austria et Sueccia in hypnis. 
¿ Euplectus nanus.

Pselophus nanus. Reich. MI. P., pag. 69, fig. 20. Gyll. ins. suec. t. 4 ,pag. 237, no14.

Euplecus Reichenbachii.Leach. Z. M. 3, 82.

Samou. 1,7 .

Denny. MI. P. 9, tab. 1, fig. 1.

Tab. 91. Fig. 2 .

Elongatus, depressus, castaneo-piceus, vix pubescens. Caput trigonum, fossis duabus profundis convergentibus antice late conjunctis impressum, in occipite elevato, nitido, foreola minima ovali observatur ; oculi nigri ; palpi restacei; antennce ferrugineæ pilosa capitis cum thorace longitudine, articulo primo cylindrareo, $2^{\circ}$ crasso splserico, 3.8 aequali lus, minimis, flobosis, coarctatis, 9 -ro iterum majoribus, lenticulari-perfoliatis, ultimo maximo ovato. Thorax capite latior et longior, antice et postice angustatus, paulo ante medium ampliatus, ad basin supra tribus foveolis sulco transverso conjunctis et in disco antico striola sat profunda abbreviata impressus. Elgtra thorace latiora et longiora, bistriata, stria suturali integra, dorsali abbreviata, ad aıgulos externos non excisa. Abdomen elytrorum longitudine aut longius, postice angustatum, segmentis æqualibus, margiuibus reflexis. Pedes mediocres testacei, tarsis pallidioribus.

Lincam vix aequat.

Habitat in Gallia, Anglia, Germania, Sueccia, sub arborum cortice. Semul Parisiis legi in ligno carpino antiquo sylva Fontis-Bellaquei. 
3. Euplectus Fischliri.

Tab. 91. Fig. 3.

Elongatus, depressus, cynnamomeus, nitidus, vix pubescens. Caput trigonum, apice bi-sinuato in medio acute reflexo, in fronte fossis duabus profondis convergentibus vix conjunctis, vertice angustato antíce producto et in disco lineola impresso, fere separatis, his duabus fossis antice et postice magis im presšis; oculi nigri, palpi pallidi; antennce testaceæ ut in $E$. nano constructa. Thorax nitidus, cordatus, antice et postice angustatus, in medio valde ampliatus, versus basin supra tribus foveolis sulco transverso conjunctis et in disco antico fossula sat profunda abbreviata impressus. Elytra thorace longiora et latiora, nitida, bistriata, stria suturali integra tenuissima, dorsali brevissima sed valde sulcato-in pressa. Abdomen elytrorum longitudine, postice angustatun, marginibus reflexis, pedes testacei, tibiis dilutioribus.

Bis lineæ tertiam partem æquat.

Habitat in Saxonia. A dom. Buquet sub hoc nomine concessus.

$\Lambda$ præcedente colòre dilutiore, capite antice acute producto, rerticis impressione longiore, valde distinctus.

** IN medio vertice rossula nULLa.

4. Euplectus Kiriı.

Euplectus Kirbii. Demny. M. P. 14, tab. 2, fig. 1.

Tab. 91. Fig. 4.

Elongatus, depressus, cynnamomeus, pubescens. Caput trigonum, fossis duabus profundis convergentibus antice late conjunctis; occipite elongato, elevato, nitido, absque 
impressionibus ; oculi nigri ; palpi pallidi ; anlennce testaceæpilosa capitis cum thorace vix longitudine ut in pracedente constructa, sed articulo ultimo paulo breviore. Thorax cordatus, capitis latitudine sed longior, antice et postice angustatus, paulo ante medium ampliatus, ad basin tribus foveolis, media maxima triangulari, sulco transverso conjunctis, et in disco antico striola abbreviata impressus. $A b-$ domen depressiusculum, elytris paulo brevius, segmentis xqualibus, marginibus reflexis. Pedes testacei pubesceutes, carsis pallidioribus.

Bis linex tertian partem æequat,

Habitat in Gallia, Anglia, pracipue in hortulanorum vaporariis. His in locis commune Parisiis legi.

\section{Euplectus sanguineus.}

Euplecus sanguineus. Denny. M. P. 1 o, tab. 1, fig. 2.

\section{Tab. $9^{2}$. Fig. I.}

Elongatus, depressiusculus, castaneo-piceus, pulescens. C'nput trigonum, foreolis duabus coeuntibus verticem clevatum angustum includentibus; oculi nigri ; palpi pallidi; antennce ferruginex, pilose, capitis cum thorace longitudine, ut in pracedente constructæ, articulo ultimo angustiore et longiore. Thorax, elytra, abdomen et pedes ut in Euplecto Kirbii.

Bis lineæ tertian partem xquat.

Vix præcedente distinctus colore ohscuriore articulo antennarum ultimo paulo longiore et elytris abdomineque paulo latioribus tantum differt (an varietas?).

Habitat in Gallia et Anglia. Cum pracedente invenitur, sed rarissime. 


\section{Euplectus Karstenu.}

Pselaphus Karstenii. Keich. M. P. 7I, fig. 21.

Gyll. Ins. suec., t. 4, pag. $238, \mathrm{n}^{\circ} 15$

Staphy linus minutus. Marshanı. i. 5 I1. 36.

-_sanguineus. Panz. F. G. 11.9.

Euplectıs Karstenii. Denny. M. P., 12, tab. ı, fig. 3.

Tab. 92. Fig. 2.

Elongatus, depressiusculus, cynnamomeus, pubescens. : Caput majusculum, thorace latius, punctatum, duabus foveolis ut in præcedentibus sed obsoletioribus impressun; vertice minus elevato in-impresso ; oculi nigri parvi ; palpi pallidi; antenne testaceæ pilosæ ut in Kirbii. Thorax cordatus, capite longior, punctatus, antice ct postice angustatus, tribus forcolis sulco connexis et lineola in disco impressus. Elytra, abdomen et pedes ut in précedentibus.

Bis linea tertiam partem æquat.

Habitat in Gallia, Anglia et Austria, sub arborun cortice et in hortulanorum vaporariis. His in locis Parisiis semel legoi.

7. Euplectus signatus.

Pselaphus sigrnatus. Reich. M. P., 73 , fig. 22.

Gyll. Ins. suecc., tom. $4,239, n^{\circ} 16$. Euplectiss - - Denny. M. P. 13, t. 1, fig. 4 .

Tab. $9^{2}$ Fig. 3.

Elongatus, depressus, cynnamomeus, pubescens. Caput trigonnm majusculum, in fronte inter antennas transverse anguste sulcatum, et in vertice duabus foveolis rotundis impressum; oculi nigri ; palpi et antenux ut in E. Karstenii. Thorax capite paulo angustior sed longior, foveola antica, 
et tribus posticis sulco curjunctis, profunde impressus. Ely̆lra, abdomen et pedes ut in pracedentibus.

Bis tertiam partem linex aquat.

Habitat in Gallia, $\Lambda$ nglia, Sueccia et Austria , sub arhortum emortuarum cortice. Ex Parisiis unicum inclividuum possideo.

\section{Euplectus Duponti.}

\section{Tab. 92. Fig. 4 .}

Elongatus, depressus, cynnamomeus, vix pubescens. caput trigonum, nitidum, thorace paulo latius, in fronte inter antennas fossula cordata lata sed parum profunda, et in vertice duabus foreolis rotundatis impressum; occipile nitido, in-impresso; oculi nigri; palpi pallidi; antennce testacea, capite cum thorace longiores, articulo $1^{\circ}$ cylindraceo-elongato, $2^{\circ}$ ovato crasso, 3-8 minimis, obconicis, minus brevibus et coarctatis, 9-10 lenticulari-perfoliatis, ultimo ovato. Thorax capite longior, nitidus, cordatus, ad basin tribus foveolis sulco connexis, et in disco lineolia lurevissima impressus. Elytra, abdomen et pedes ut in E. Karstenii.

Bis tertiam partem linea parum superat.

Hahitat in Gallia. Parisiis unicum individuum in ligno putrido inveni.

llace species congeneribus valde affinis, capitis. foreola antica latiore, et antennis longioribus gracilioribusque diversa.

\section{Euplectus bicolor.}

Euplectus Licolor. Denny. M. P. 17, t.1b. 2, fig. 3. Pselaphus glabriculus. Gyll. Ins. suecc., t. 4, 236, 11013.

Tab. 93. Fig. 1.

Elongatulus, depressus, nigro-piceus, pube licvi tectus. capnt trigonum thorace angustius, in fronte duabus 
foveolis convergentibus antice conjunctis impressum ; verlice elevato in-impresso; ore testaceo; oculi nigri parvi; palpi pallidi ; antennce testacex capitis cum thorace vix longitudine, ut in $E$ : nano constructæ, sed breviores et magis coarctatæ. Thorax cordatus, antice et postice angustatus, versus basin foveola minima et utrinque in latere singula tenuissima, et in disco alia etián tenuissima vix perspicua, notatus, lateribus sulco brevi impressis. Elylra thorace multo latiora et longiora, bi-striata, stria suturali integra, dorsali dimidiata. Abdomen elytrorum longitudine, marginibus reflexis. Pedes breviusculi, rufo testacei, tarsis dilutioribus.

Lineæ dimidiam partem paulo excedit.

Habitat in Gallia, Anglia et Sueccia. Parisiis in ligno putrido semel inveni insula Louviers dicta.

\section{Euplectus ambiguUs.}

Pselaphus ambiguus. Reich M. P., 67, fig. 19 .

$$
\text { Gyll. Ins. suecc., tom. } 4,236, \mathrm{n}_{0} 12 \text {. }
$$

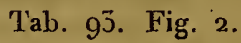

Elongatulus, depressus, nigro-piceus, pube levi téctus. Caput trigonum, thoracis latitudine, in fronte duabus fossulis convergentibus antice conjunctis impressum, vertice elevato in-impresso; oculi nigri ; palpi pallidi; antennce ferrugineo-testaceæ, clava obscuriore, ut in præcedente constructa. Thorax quadrato-rotundatus, antice et postice angustatus, versus basin tribus foveolis sulco transverso conjunctis impressus, disco antico lævi. Elytra, abdomen et pedes ut in præcedente, elytrorum tamen stria dorsali breviore.

Lineæ dimidiain partem paulo superat.

Habitát in Gallia, Germania, Sueccia. Parisiis in loco Bondy semel legi, mense junio. 
11. Euplectus púsillus.

Euplecus pusillus. Denny. M. P., 15, tab. 2, fig. 2.

Tab. 93. Fig. 3.

Elongatulus, depressus, nigro-piceus, pube lævi tectus. Caput trigonum, thoracis latitudine, in fronte duabus foveolis convergentibus antice conjunctis inpressum, vertice elevato in-impresso ; oculi niggri ; palpi pallidi; antennce ad basin ferrugineo-testacex clava obscuriore ut in duobus pracedentibus constructa. Thorax cordatus, antice et pracsertim postice angustatus, ad basin tribus foreolis sulco transverso connexis notatus, disco antico lævi. Elytra, aldomen et pedes ut in E. ambiguo.

Lineæ dimidian partem æquat.

Pracedenti paulo breviore, attamen valde affinis. Thorace corda to postice angustato vix distinctus. An tantum ambigui varietas?

Habitut in Gallia et Anglia. Parisis unicum individuum in prato depresso legii.

12. Euplecti's minetissimus.

Tab. 93. Fig 4.

Elongatulus, depressus, cymnamomeo-castaneus. Caput trigonum valde antice productum, in vertice duabus fossulis rotundatis impressum ; oculi niggri ; palpi pallidi ; antenn ${ }^{2}$ testaceo-flavescentes ut in precedentibus, sed breviores. Thorax rotundatus capite latior, latitudine longitudinem xquat, ad basin tribus foreolis, foveola media maxima, notatus, his tribus foveolis sulco profundo et lato connexis, fere in unica confusis, disco antico levi. Elytra bi-striata, striis valde impressis. Abdomen latum, depressun, mar- 
gimibus reflexis. Pedes mediocres testaceo-flavescentes, lirrsis dilutioribus.

Lineæ tertiam partem vix requat.

Habitat in Sicilia. Ex museo dom. Helfer, qui ad descriptionem benevole communicavit.

Euplectis ambiguo et pusillo valde aflinis, capite anguste producto, duabus foveolis rotundatis impresso, thorace breviore et tandem brevitate corporis certe distinguendus.

\section{B. Capite in-impresso.}

\section{Euplectus leiocephalus:}

Tab. 93. Fig. 5 .

Elongatus, depressus, castaneo-cynnamomeus. Cuput parvum trigonum, in-impressum ; oculi. nigri ; palpi pallidi; antennce testáceæ ut in piæcedentibus constructæ, sed breviores et clava crassiore. Thora.x cordatus, capite longior et latior, antice et postice angustatus, ad basin tribus foveolis, media maxima, sulco angusto valde bisinuato transverse connexis. Elytra antice thorace parum latiora, postice magis quam in præcedentıbus ampliata, vage subtriangularia, bi-striata, stria suturali integra, dorsali abbreviata. Abdomen latum, depressum, marginibus reflexis. Pedes pallidi, tarsis dilutioribus. -

Dimidiam lineæ partem æquat.

Habitat in Gallia meridionali. Unicum individuum ex agris Telonis possideo a domino de laporte generose concessum.

A cæteris capite in-impresso et elytris minus parallèlis valde differt. 
14. Luplectus eastrombookiands.

Euplectus éasterbrookianus. Ieach. Zool. Journ. 2 , 445.

Insecto inviso, hic descriptionem: dom. Leach refero:

"Corpore toto intense ferrugineo ; antennis, palpis, pedi" busque pallidioribus; thorace ruguloso; elytris puncta" tulis.

"Habitat in Danmoniæ nemoribus rarissimus.

"Ex museo dorn. Easterbrook. "

2. Sectıo. Antennis sex-articulatis.

12 Genus. CLAVIGER.

Claviger, Müller, Panzer.

Caput elongatum; oculi latentes aut nulli; palpi maxillares brevissimi, sub cylındrici, indistincte articulati, apice bi-ı1!guiculati; autenure sex articulatæ, duobus primis articulis minimis et ultimo maximo cylindraceo, apice truncalo. Thurax fere spherico. Elylra sul-lliangularia, ad augulos externos plicata. Abdomen latun, prino segmento maximo, in disco late depresso, marginibus reflexo-elevatis. Pedes crassiusculi, tarsis tri-articulatis, duobus primis articulis minimis, ultimo maximo uni-unguiculato.

1. Claviger foveolatus.

Claviger foveolatus. Müller, in Germ. mag. 3, pag. $69 \mathrm{ct}$ sequent.

testaceus. Panz. Faun., 4.9, fig. 3.

Preysler, Ins. Boh. $n^{\circ} 65$, pag. (iS, - t. 3 , fig. 5 , a. b.

Tab. 94. Fig. 1.

Elongatus, antice angustatus, rufo testaceus. Capul prorectum, posterius attenuatum, angulis posticis longius pi- 
losis, pilis conniventibus spinulam mentientibus. Oculi nulli aut imperspicui ; palpi maxillares brevissimi ; antenna pilis rigidis tectæ, capite paulo longiores, articulis $\mathrm{I}-2$ globosis, primo minimo in fossula laterali capitis latente , 3 sub-hemispherico, 4 ob-hemispherico , 5 iterum sub-hemispherico, his tribus fere æqualibus, ultimo maximo cylindraceo apice truncato. Thorax capite longior et duplo latior splıærico-ovatus, in lateribus leviter rotundatim impressus, et supra ad basin fossula rotundata notatus. Elytra breviora antice thorace parum latiora, postice valde ampliata, subtriangularia, angulis externis posticis plicatis et plica pilis rigidis flavescentibus ornata. Abdomen latum, obtusum, quasi inflatum, marginibus elevatis, segmento $1^{\circ}$ maximo in disco fossula profunda semi-ovali impresso. Pedes validi , femoribus sub-cylindricis, tibiis sub-compressis tarsis angustis; in non nullis femoribus et tibiis dente parro armatis (an $\sigma^{\top}$ ).

Lineam paulo excedit.

Habitat sub lapidibus in societate cum formicis..... in Sueccia, Germania et Belgica.

\section{Claviger longicornis.}

Clavigè longicornis. Müller. In Germ.- mag. 3, pag 85 et sequent.

Sturm. Cat. mein. Ins. sam.

Panz. F. J. E. Fasc. 7.

Tab. 94. Fig. 2 .

Elongatus, antice angustatus, rufo-castaneus. Caput prorectum posterius attenuatum, angulis posticis longius pilosis, pilis conniventibus spinulam mentientibus; oculi nulli aut imperspicui ; palpi maxillares tenuissimi; antennce pilis rigidis tectæ, longitudine capitis cum thorace, in fos- 
sula laterale capitis inserte, articulo primo minimo spharico, 2 sub-hemispherico, 3-4-5 cylindraceis gradatim minoribus (3 multo majore), 6 præcedentibus latiore, cylindraceo, apice truncato. Thorax capitis longitudine sed duplo latior, spherico-ovatus, in lateribus leviter rotundatim impressus, et supra versus basin fossula oblonga notatus. Elytra ut in pracedente sed latiora. Abdomen latum, obtusum, quasi inflatum, marginilus elevatis, seggmento primo maximo, in disco foveola profunda lata in fundo duabus lineolis impressa, notato. Pedes validi, $f e$ moribus subcylindraceis, tibiis subcompressis, tarsis angustis. In nonnullis tibix antice parro dente sunt armatx. $\left(A n \gamma^{*}\right)$

Lineain paulo excedit.

Habitat cum formicis in Germania rarissimus.

A precedente capite longiore antennis aliter construclis et aljdonine fossula latiore impresso valde distinctus.

\section{Secrio. Antennis uni-articulatis.}

\section{Genus. ARTICERUS '.}

Aiticerus, Dalmau.

Antennæ prorectæ, clava ${ }^{-}$elongara, cylindrica, inarliculata, apice truncata. Oculi laterales, distincii, prominuli. Habilus Clavigeri, ore clauso; elytris dimidiatis, ablonnine magno, marginato. Genus memorabile, ad coleopterorum finem forte ponendum, clavigero certe nimis afline, sed distinrtum antennarum clava aut vere inarticulata, ant articulis adeo salten connatis, ut distingui haud queunt; cun in Clavigero antennæ constant articulis 6 , inæqualibus, discretis et valde distinctis. Oculi in articero valde conspicui, ad latera capitis siti; in Cla. vigero aut plane nulli, aut adeo oculati, ut ncc oculatissino

- Hoc genere inviso quod in illo dom. Dalman scripsit accurate hic refero. 
Müllero nec mihi unquam-successum est eorum rudimenta de. tegere. - A Psclapho onnino distat articerus forma et antennarun et capitis, atque tarsis aliter construclis.

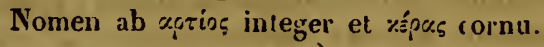

\section{Articerus aryatus.}

Articerus armatus. Dalman om Insect. innes. i copal, pag. 23 , tab. 4 , fig. 12 .

Tab. 94. Fig. 3.

Ferrugincus antennarum clava cylindrica truncata longitudme capitis; pedum intermediorum fcmoribus bi-dentatis, tibiis uni-dentatis.

Habitat - - specimina duo copalo inclusa lustravi, magnitudine, habitu et colore similia, quorum unum pedes intermedios distincte dentatos habet, alterum vero pedes omnes contractos, quare dignoscere nequeo an sint armati an inermes, quod de pedibus posticis utriusque specininis etiann valet.

Clavigero testaceo dimidio minor, gracilior. Corpus totum ferrugineum vel testaceum, nitidum, oculis solis nigris , punctisque duobus dorsalibus obscuris. Antenne aliquantum ante oculos insertæ; artiçulus primus parvus, obsoletus ; secundus maxinus, longitudine capitis, crassitie feimoris, basi tenuior, deinde cylindricus, apice truncatus, nec incrassatus. Caput thoracis longitudine, teres antice crassius; vertex intra oculos punctis duobus impressis. Oculi nigri, laterales prominuli, in medio capite siti, onnino distincti. Thorax quam latus manifeste longior , in medio aliquantum dilatatus, antice angustatus, canalicula dorsali obsoleta Scutellum nullum. Elytra horace dimidio saltem longiora, et jam hasi illo latiora, posterius valde dilatita, apice truncata, abdominis tantummodo to rtian 
partem obtegentia, supra plana lævia. Scripturam quandam detegere nequeo, nisi forte lineolam abbreviatam utrinque juxta scutellum, atque alteram intra-marginalem, longiorem. Abdomen pone elytra eorum latitudine, sed illis manifeste longius, marginatum, apice rotundatum; segmentum primum breve, transversum, punctis duobus dorsalibus nigris; posterior abdominis pars, sub-pulvillata, lavis. Corpus subtus concolor. Segmenta abdominis supra liaud distinguenda, subtns quinque. Pedes corpore paulo pallidiores; antici mutici; intermediorum femora sub-clavata, margine postico pone medium bi-dentato, inter dentes sub-emarģinata; tibice ejusdeın. paris pone medium denticulo minuto intus armatæ. Pedes postici iterum mutici videntur, quod tamen pro certo haud dicamus, cum in nostris speciminibus sub corpore contracti, et examinatu difficiles. 'Tarsi brevissimi, articulo ut videtur unico; - sed articulis tribus constare ex analogia suspirare licet, secundum observata Mülleri in Clavigeri species. 


\section{T'ABULARUM EXPLICATIO.}

Tab. 78. Fig. 'I. Metopias curculionoides. I $a$. Antennæ extremitas. I $b$. Palpus maxillaris. I $c$. Tarsus.

Fig. 2. Chennium biluberculatum. 2 a. Antenna. 2 $b$. Pes. 2 c. Palpus maxillaris.

Fig. 3. Tyrus mucronatus. 3 a. Antenna. 3 b. Palpus maxillaris. 3 c. Pes anticus. $3 d$. Pes intermedius.

Tab. 79. Fig. 1. Ctenistes palpalis. I a. Antenna. I b. Palpus maxillaris.

Fıg. 2. Clenistes Dejeanii. 2 a. Antenna. 2 b. Palpus maxillaris.

TaJ. 8o. Fig. 1. Pselaphus Heisei. I a. Antenna. I b. Palpus maxillaris cum maxilla. I $c$. Mandibula. $1 d$. Labrum. 1 e. Ligula cum palpis labialibus.

Fig. 2. Pselaphus Herbstii. 2 a. Palpus maxillaris.

Fig. 3. Pselaphus longicollis. 3 a. Palpus maxillaris.

Fig. 4. Pselaphus dresdensis. $4 a$. Palpus maxillaris. Tal. 8. Fig. 1. Bryaxis longicornis. I a. Antenna. 1 b. Palpus maxillaris cum maxilla. $1 c$. Mandibúla. I $d$. Labrum. I $e$. Ligula cum - palpis labialibus. I $f$. Pes anticus.

Fig. 2. Bryaxis sanguinea. 2 a. Antenna.

Fig. 3. Bryaxis fossulata. 3 a. Antenna.

Tab. 82. Fig. I, Bryaxis hematica. I $a$, I $b$, I $c$. Varietatum $B$. perforatce, $B$. sinuatce et $B$. bidenticulate abdomina.

Fig. 2. Bryaxis abdoninalis.

Fig. 3. Bryaxis depressa.

Tab. 83. Fig. 1. Bryaxis Lefebvrei. r a. Pes anticus.

Fig. 2. Bryaxis rubripennis. $2 a, 2 b$. Pedes anticus et intermedius.

Fig. 3. Bryaxis xanthoptera. $3 a, 3 b$ Pedes anticus et intermedius.

Fig. 4. Bryaxis Gory.

Tab. 84. Fig. 1. Bryaxis impressa.

Fig. 2. Bryaxis antennata. 2 a. Antenna. 
Fig. 3. Bryaxis juncorum.

Fig. 4. Bryaxis tomentosa.

Tab. 85. Fig. 1. Bythinus Curtisii. I a. Antenna. 1 b. Palpus maxillaris cum maxilla. I $c$. Mandibula. I $d$. Labrum. 1 e. Ligula cun palpis labialibus.

Fig. 2. Bythinus luniger. $2 a$. Antenna. $2 b$. Palpus maxillaris.

Fig. 3. Bythinus Burellii. 3 a. Antenna. 3 b. Palpus maxillaris.

Fig. 6. Bythinus securiger. 4 a. Antenna. 4 b. Palpus maxillaris.

Tab. 86. Fig. 1. Bythinus nodicornis. I a. Antenna. I b. Palpus maxillaris.

Fig. 2. Bythinus bulbifer. 2 a. Antenna. 2 b. Palpus maxillaris.

Fig. 3. Bythinus glabricollis. $3 a$, Antenna. 36 . Palpus maxillaris.

Fig. 4. Bythinus macropalpus. 4 a. Antenna. $4 b$. Palpus maxillaris.

Tab. 87. Fig. I. Bythinus globulipalpus. I $a$. Antenna. I b. Palpus naxillaris.

Fig. 2. Bythinus clavicornis. 2 a. Antenna. 2 b. Palpus maxillaris.

Fig. 3. Bythinus Cheurolati. 3 a. Antenna. 3 b. Palpus maxillaris.

Fig. 4. Bythinus puncticollis. $4 a$. Antenna. $4 b$. Palpus maxillaris.

Tab. 88. Fig. I. Tychus niger. I $a$. Antenna maris. I $b$. Antenna foeminx. I $c$. Palpus maxillaris.

Fig. 2. Trimium brevicorne. $2 a$. Antenna. $2 b$. Palpus maxillaris.

Tab. 89. Fig. 1. Batrisus formicarius. I $a$. Antenna. I $b$. Palpus maxillaris cum maxilla. I c. Mandibula. I $d$. Ligna cum palpis labialibus. I e. Labrum.

Fig. 2. Batrisus De Laporti. 2 a. Antenna.

Fig. 3. Batrisus Brullei. 3 a, Antenna. 
Fig. 4. Batrisus oculatus. $4 a$. Antenna.

Tab. 99. Fig. 1. Batrisus venustus.

Fig. 2. Batrisus albionicus. 2 a. Antenna. $2 b$. Palpus inaxillaris.

Fig. 3. Batrisus lincaticollis. 3 a. Antenna.

Fig. 4. Batrisus Buqueti.

Tab. 91. Fig. 1. E'uplectics sulcicollis. x a. Antenna.

Fig. 2. Euplectus nanus. 2 a. Antenna. $2 b$. Mandibula. $2 c$.'Palpus maxillaris cum maxilla. 2 d. Labrum. 2 e. Ligula cum palpis labialibus.

Fig. 3. Fupleclus Fischeri.

Fig. 4. Euplectus Kirbii.

Tab. 92. Fig. 1. Euplectus sanguineus.

Fig. 2. Euplectus Karstenii.

Fig. 3. Euplectus signatus.

Fig. 4. Euplectus Duponti. 4 a. Antenna.

Tal. 95. Fig. 1. Euplectus bicolor.

Fig. 2. Euplectus ambiguus.

Fig. 3. Euplectus pusillus.

Fig. 4. Euplectus minutissimus.

Fig. 5. Euplectus leiocephalus. 5 a. Antenna.

Tab. 94. Fig. I. Claviger foveolatus. I $a$. Antenna. $1 b$. Maxila cum palpo maxillari. I c. Mandibula. i $d$. Ligula. 1 e. Labrum. i $f$. Pes intermedius.

Fig. 2. Claviger longicornis. 2 a. Antenna. 2 b. Pes intermedius.

Fig. 5. Articerus arnatus. 


\section{INDEX ALPHABETICUS.}

\section{ANTIIICUS.}

diesdensis.

$$
\text { Pages. }
$$

$21-52$ sanguineus.

ARCOPAGUS.

bullifer.

clavicornis.

37 glabricollis.

40 puncticollis.

AR'TICERUS. $6 \overline{3}$

armatus.

64

BATRISUS. 45

albionicus.

Br.ullei.

Buqueti.

De Laporti.

49 formicarius. 46

47 lineaticollis. 50

5o oculatus. $\quad 48$

46 venustus. 48

BOSTRICHUS.

anomalus.

37

BRYAXIS. $2 \tilde{J}$

abdominalis.

antennata.

bidenticulata.

depressa.

fossulata.

Gory.

Jææmatica.

inpressa.

juncorum.

Lefebrrei.

bulbifer.

Burellii.

Chevrolati.
27 longicornis.

3 nigriventris.

24 48

27 perforata. 27

25 rubripennis. 29

25 sanguinea. 25

3o sinuatn. 27

26 sulcicollis. $\quad 52$

31 tomentosa. 33

52 tripunctata. 25

28 xantioptera. $\quad 29$

BITHINUS. 55

37 clavicornis. $\quad 40$

55 curtisianus. 34

41 Curtisii. ib. 
glabricollis.

globulipalpus.

luniger.

macropalpus.

1'ages

38 nodicornis.

39 puncticollis.

35 securiger.

39

CHENNIUM. 14

bituberculatum.

14

CLAVIGER. 6 r

foveolatus.

longicornis.

6 I testaceus.

6 I

62

\section{CTENISTES. 17}

Dejeanii.

i palpalis.

17

$D I O N Y X$.

Dejeanii.

18

EUPLECTUS. 5i

ambiguus.

brevicornis.

58 leiocephalus.

60

44 minutissimus. $\quad 59$

bicolor.

Duponti.

easterbrookianus.

Fischeri.

Karstenii.

Kirbii.

57 nanus.

ib. pusillus.

6r Reichenbachii.

54 sanguineus.

56 signatus.

54 sulcicollis.

\section{KUNZEA .}

nigriceps.

42

METOPIAS. 13

curculionoides.

I3

PSELAPHUS. I 9

albionicus.

ambiguus.

brevicórnis.

49 brevipalpis.

58 bulbifer.

20

44 castaneus. 
clavicornis. dresderisis.

dresdensis. detritus. crygaster. fossulatus. glabricollis. glabriculus. hamaticornis.

Heisei.

Heisei.

Herbstii.

impressus.

insignis.

Karstenii.

juncorum.

crassicornis.

minutus.

brevicorne.

niger.

mucronatus.
IXDEX ALPHABETICUS.

71

Pages

40 lineaticollis.

Pagey

25-52 longicollis.

22 mucronatus. 16

43 nanus. $\quad 53$

19 niger. 45

25 nodicornis. ib.

r. 9 - oculatus. $\quad 48$

57 ruficornis. 43

35 sanguineus. $\quad \mathbf{1 6 - 2 5}$

19 securiger. $\quad 36$

20-22 signatus. $\quad 56$

20 sulcicollis. 52

3 r venustus. $\quad 48$

16 xanthopterus. 29

56

REICHENBACHIA.

32

STAPIIYLINUS.

I6 sanguincus.

56

$16-56$

TRIMIUM. 44

44

TYCHUS. 42

43

TYRUS. 15

16

FINIS. 


\section{ERRATA.}

Page 6, lig. 21. Pselaphiis; lisez Pselaphis.

Page 6, lig. 23. Palpibus; lisez Palpis.

Page 13, lig. 17. Tab. 79; lisez Tab. 78.

Page 14, lig. 26. Tab. 79 ; lisez Tab. 78.

Page 16 , lig. 10. Tab. 79 ; lisez Tab. 78 .

Page 16, lig. 11. Elongatulum, convexum; lisez Elongatulus, convexus.

Page 18, Note. Audinot; lisez Audinet.

Page 39, lig. 2. Ducos; lisez Duros.

Page lio, lig. 5. Ducos; lisez Duros.

Page 53, lig. 11. Ovali; lisez ovalis.

Planche 83,6 G. 3. Aubé; lisez Ricich. 


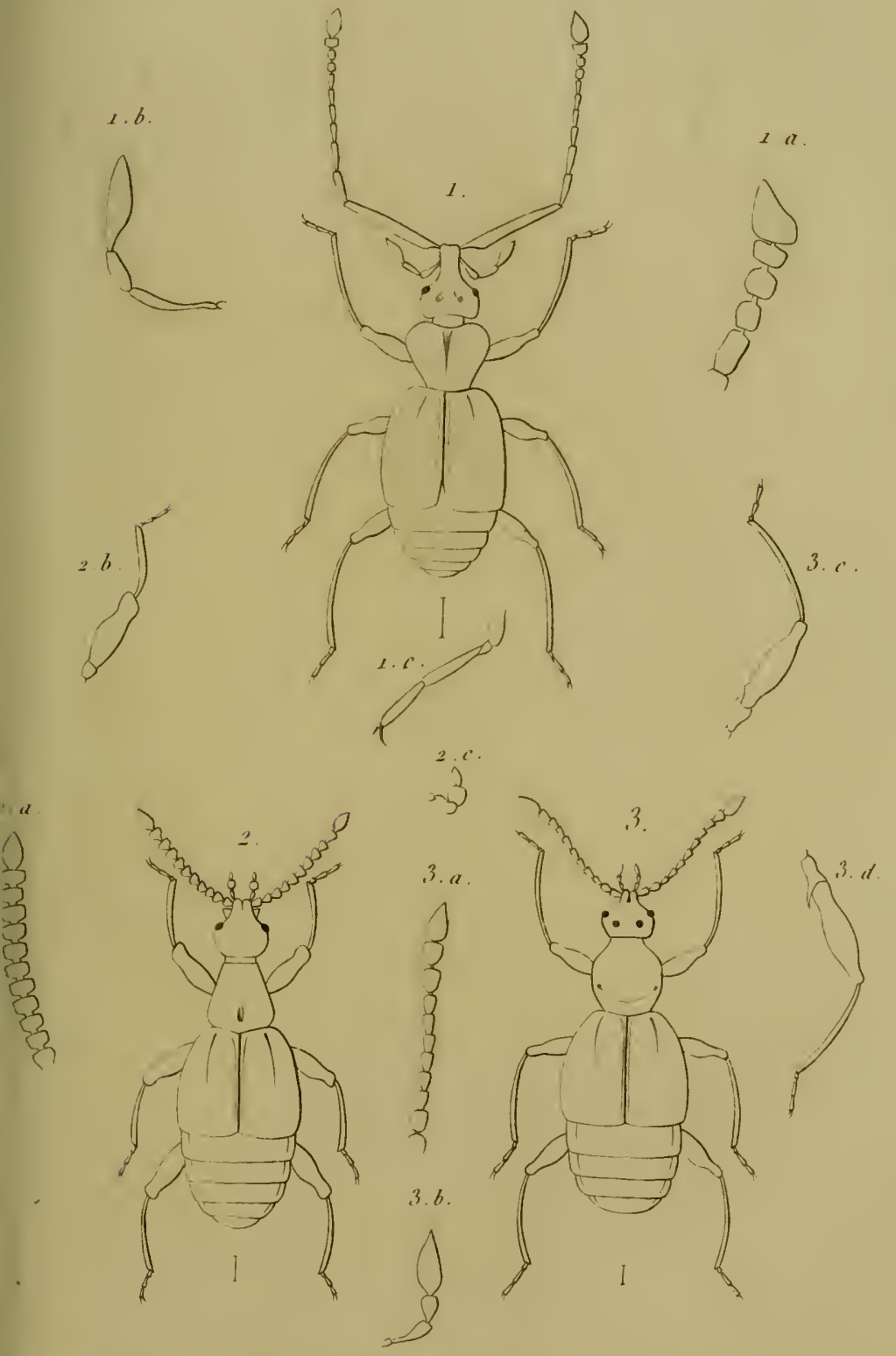

7. Metopuas curculionoides, Gơny. 2. Chenwium biubercululum, Lau. 3. Trrus mueronalus, Giyll. 


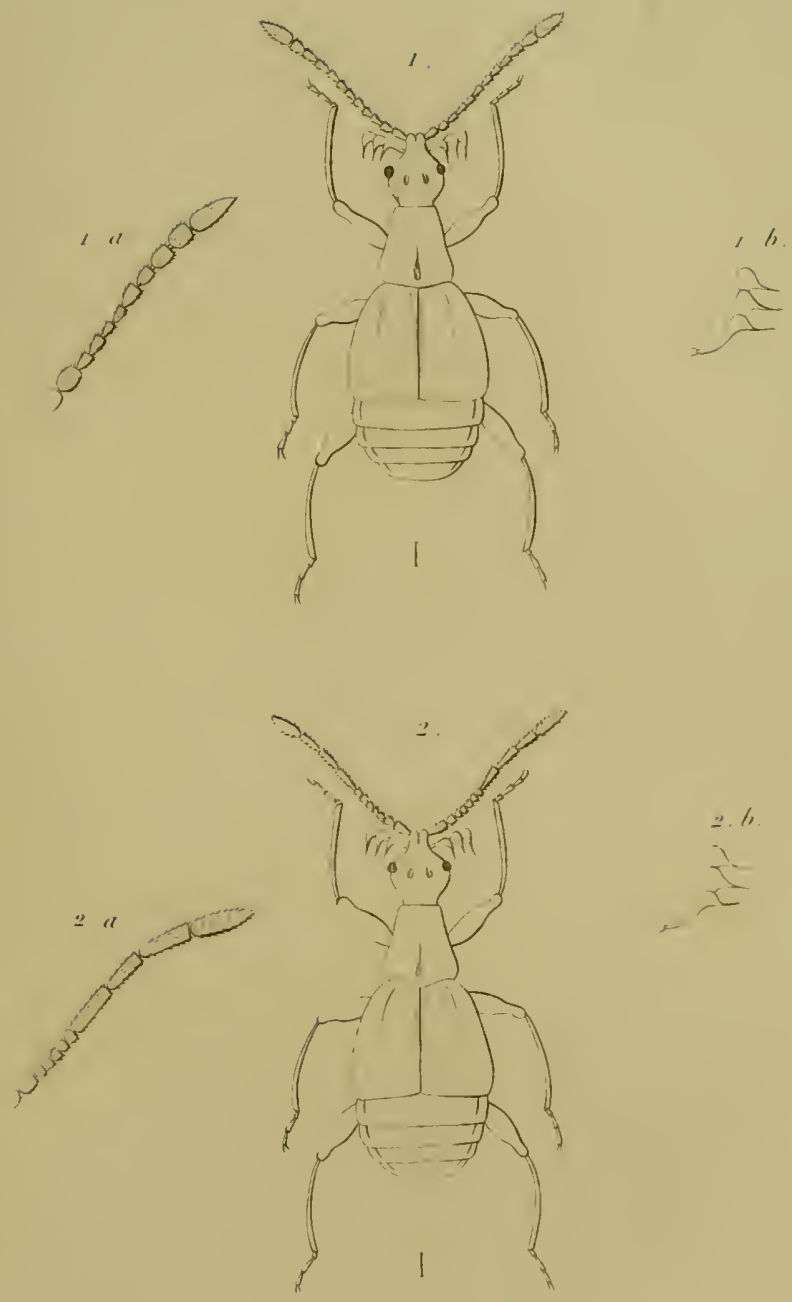

(renistes

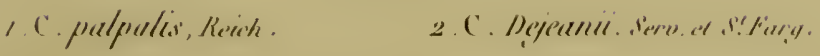





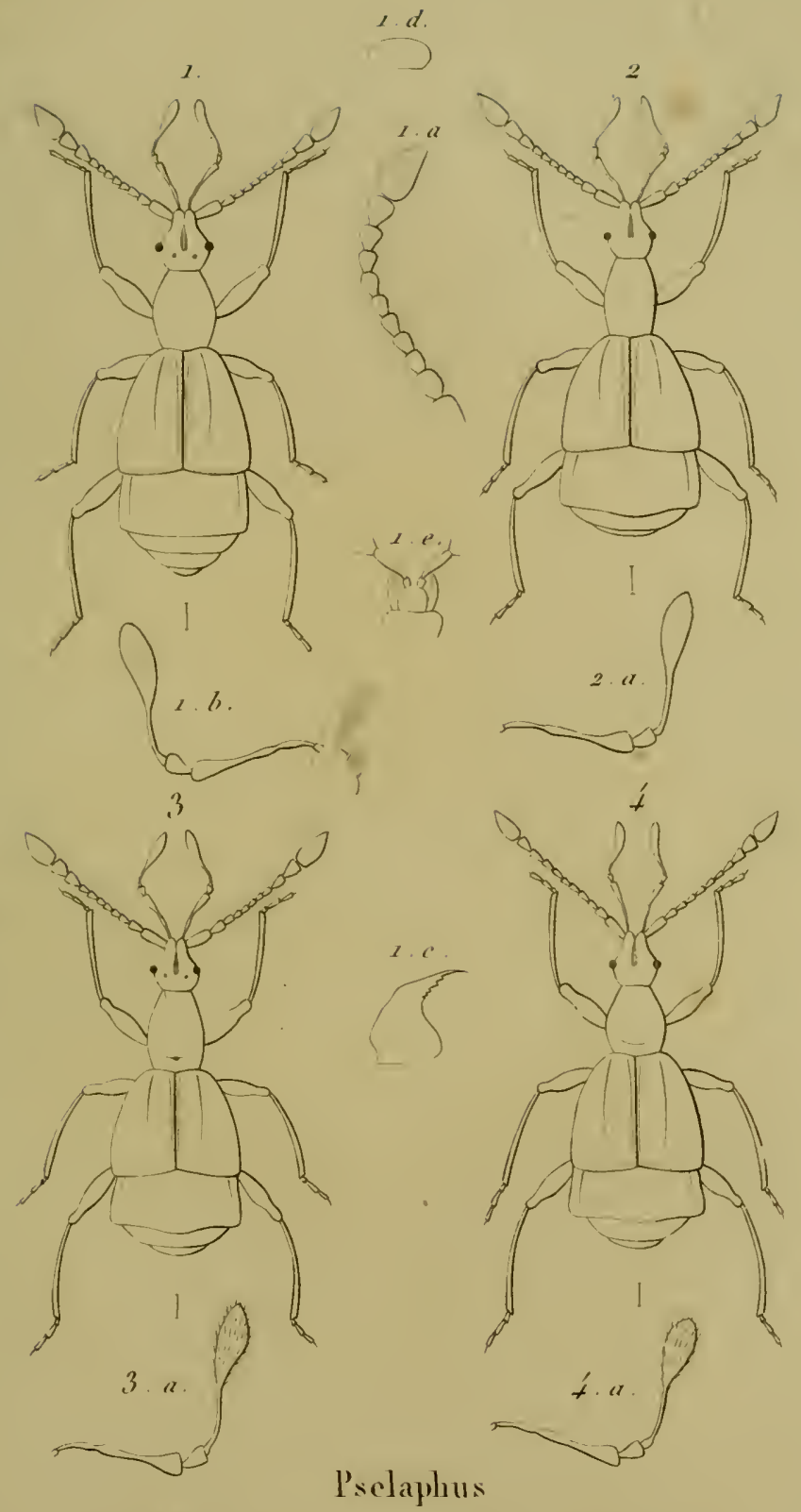

1. P. Heisei, Herbise.

3. J. Jemengientlis, Rewh
2. P Merhislii. Revirh.

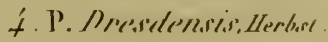




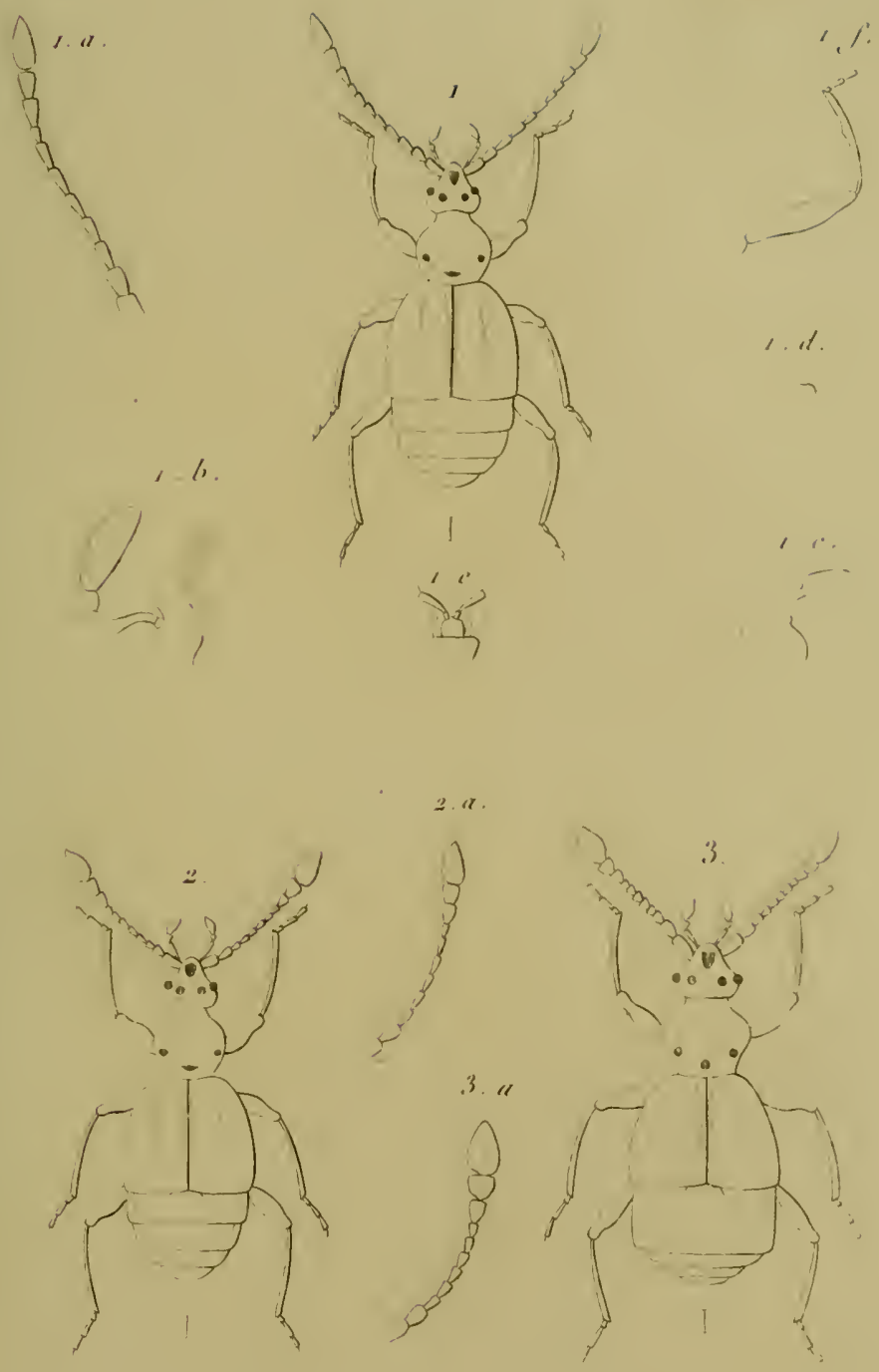

Buaxis

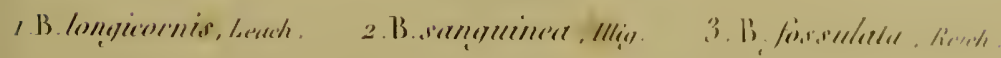




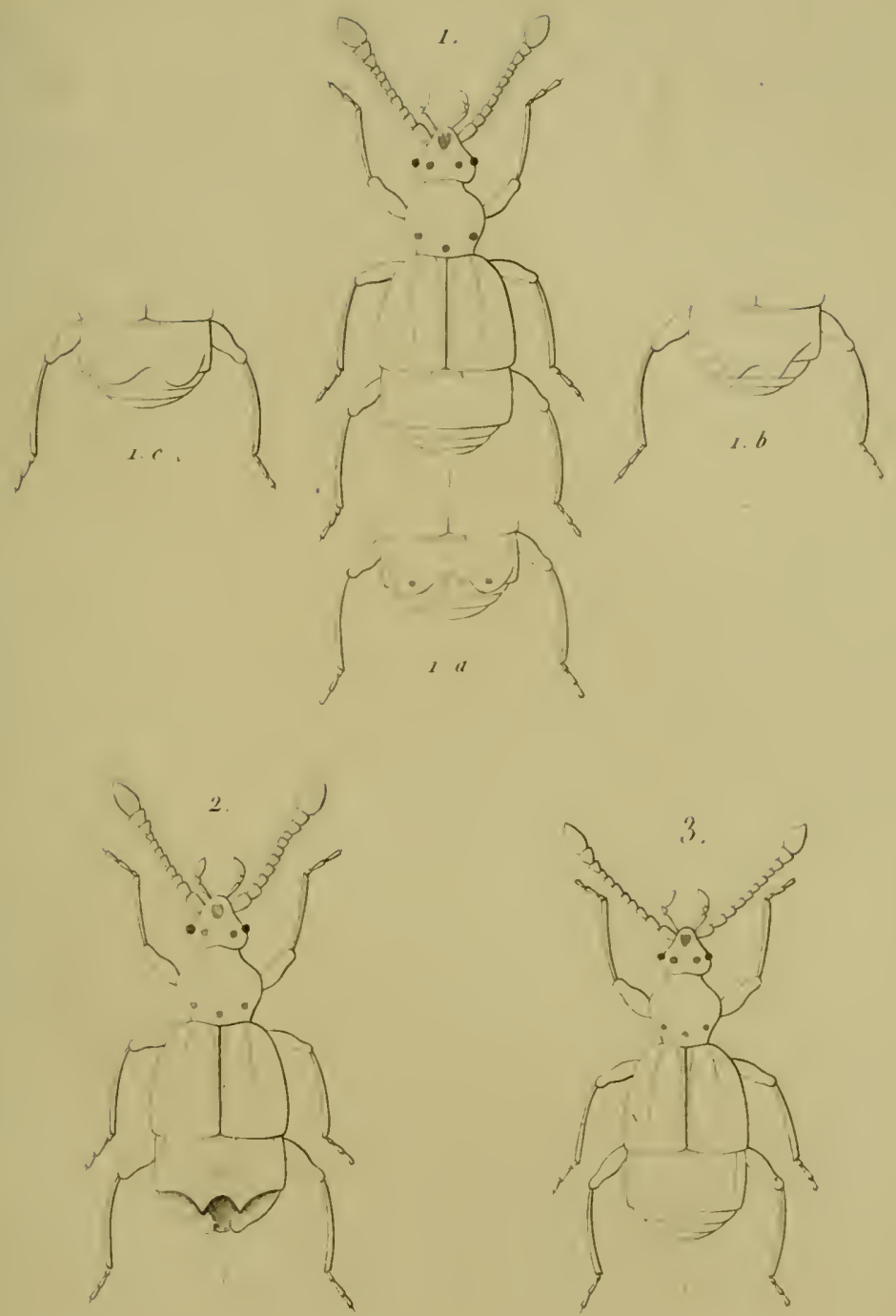

Bryaxis

1. B. harmatica Reich. 2. B. abdominalis Intio'.

3. B. Depresessa. Aubic. 


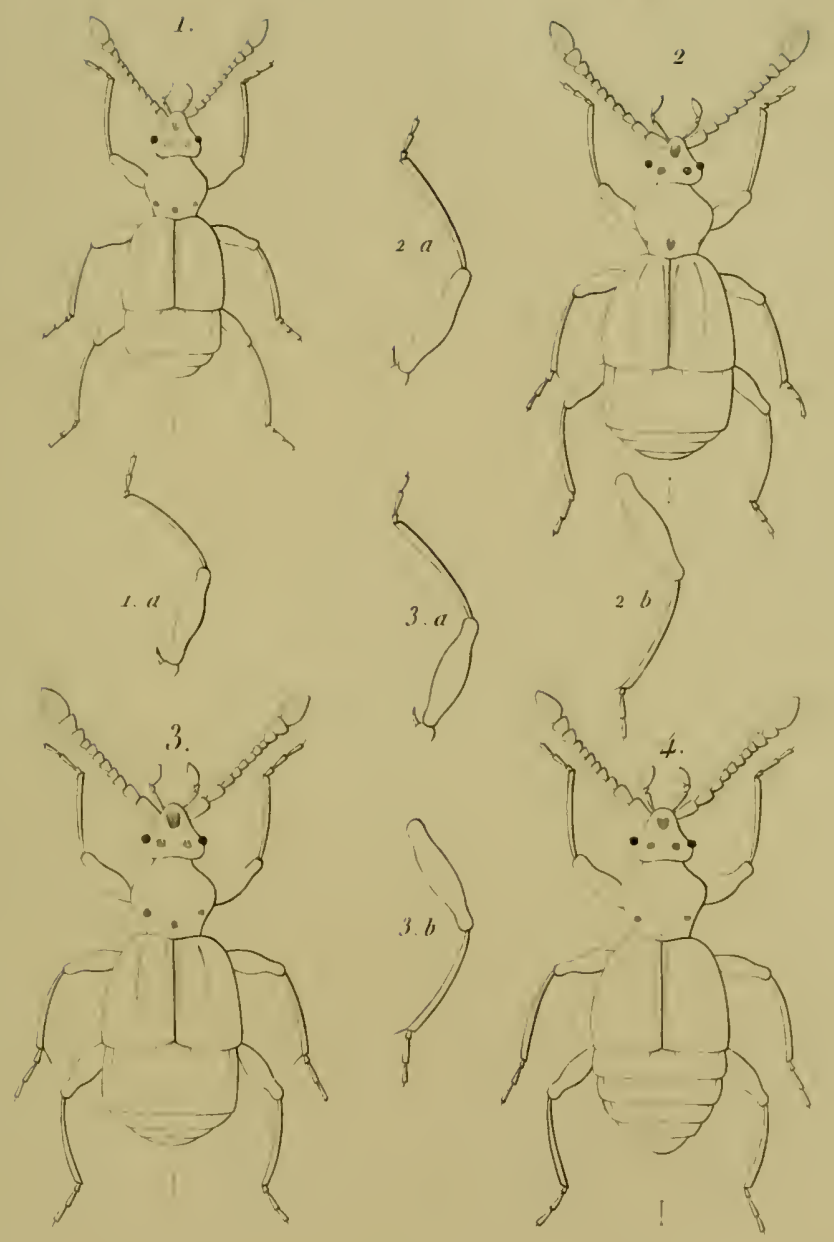

\section{Bryaxis}
1 B. I.efeburei - tubé.
3. B. rubripennis . tubic
3. B. canthoptera - tubé. 4. B. Gory - tubí. 


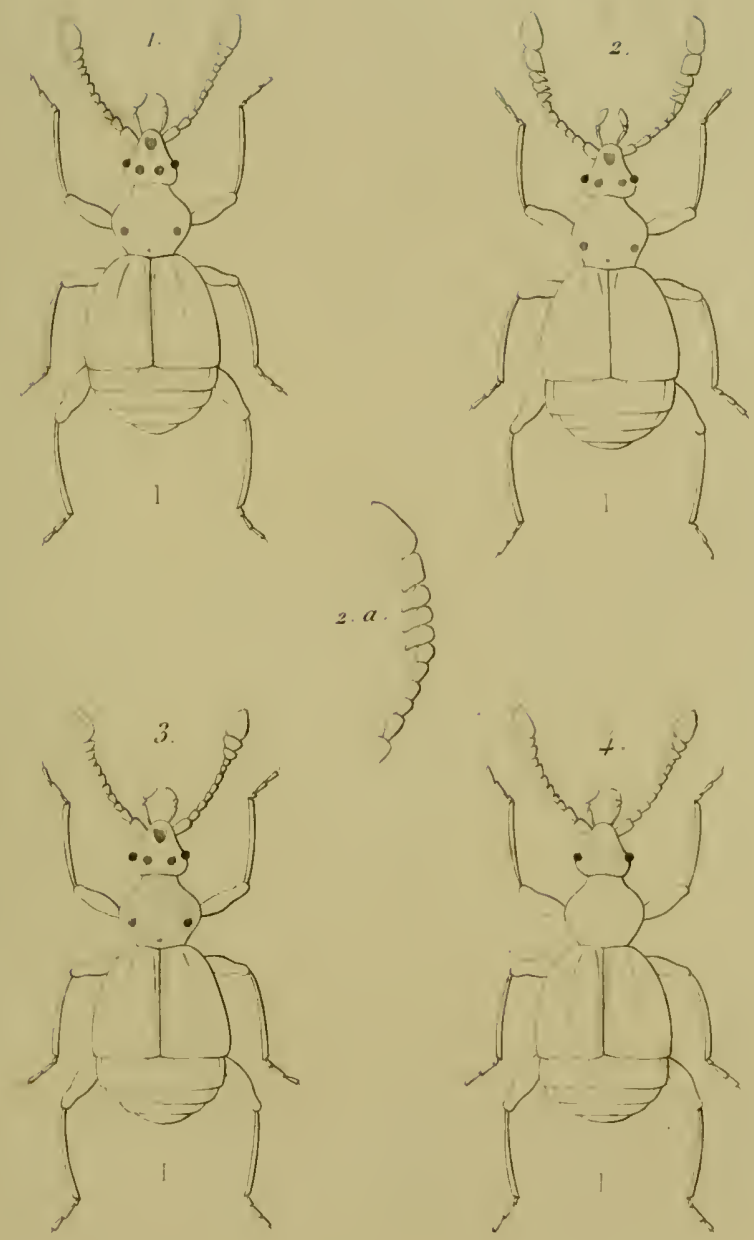

Brvasis
1. B. impressa Panz
2. B. antenmata tubé.
3 B. juncomrum Leach.
4. B. Comentosa Dej. 



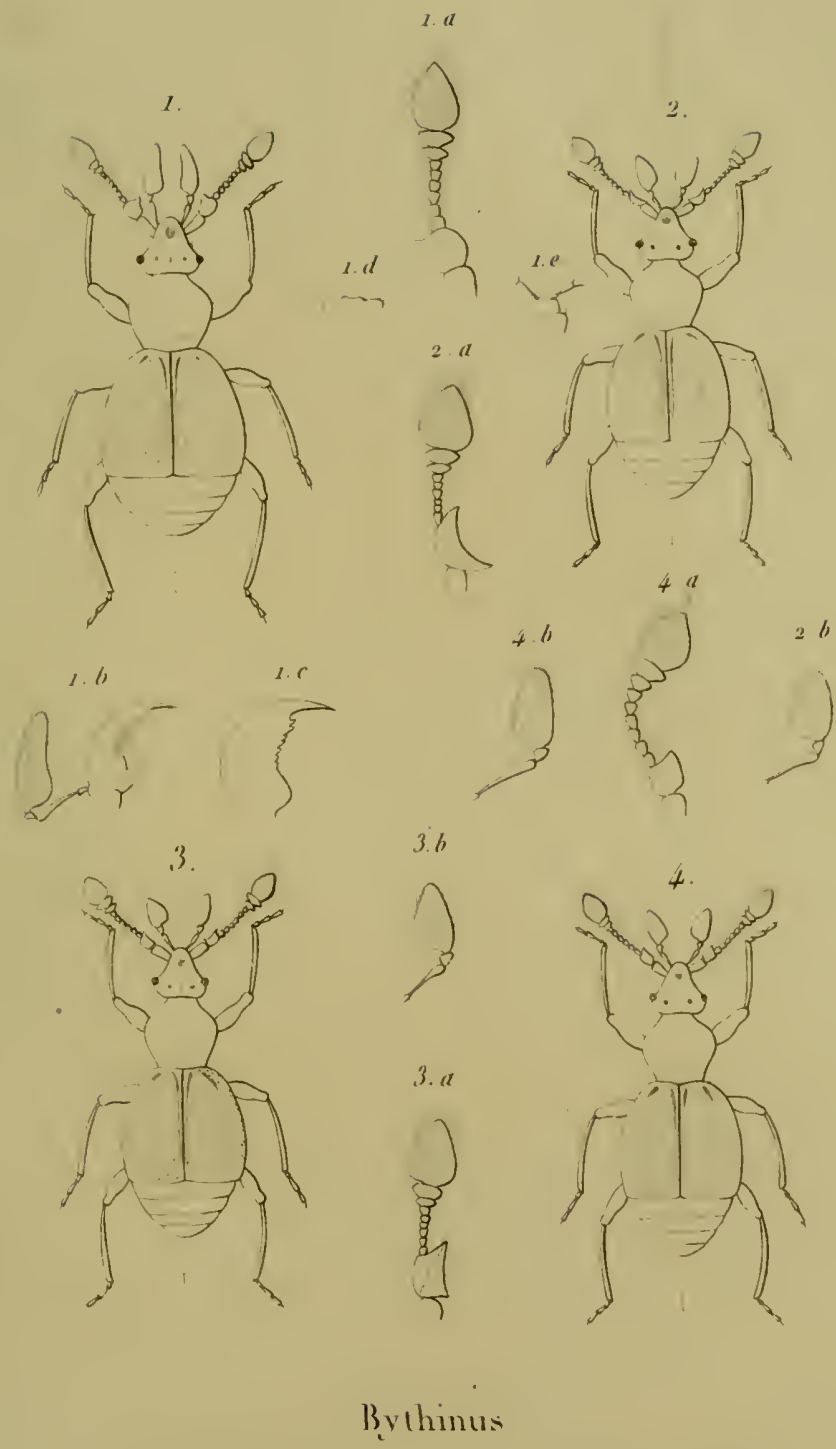

1. B. Ciurlisil . Leneh

2. B. luniger Aubie.

3. B. Burellii. Menny.

4. B. securiger. Resich. 


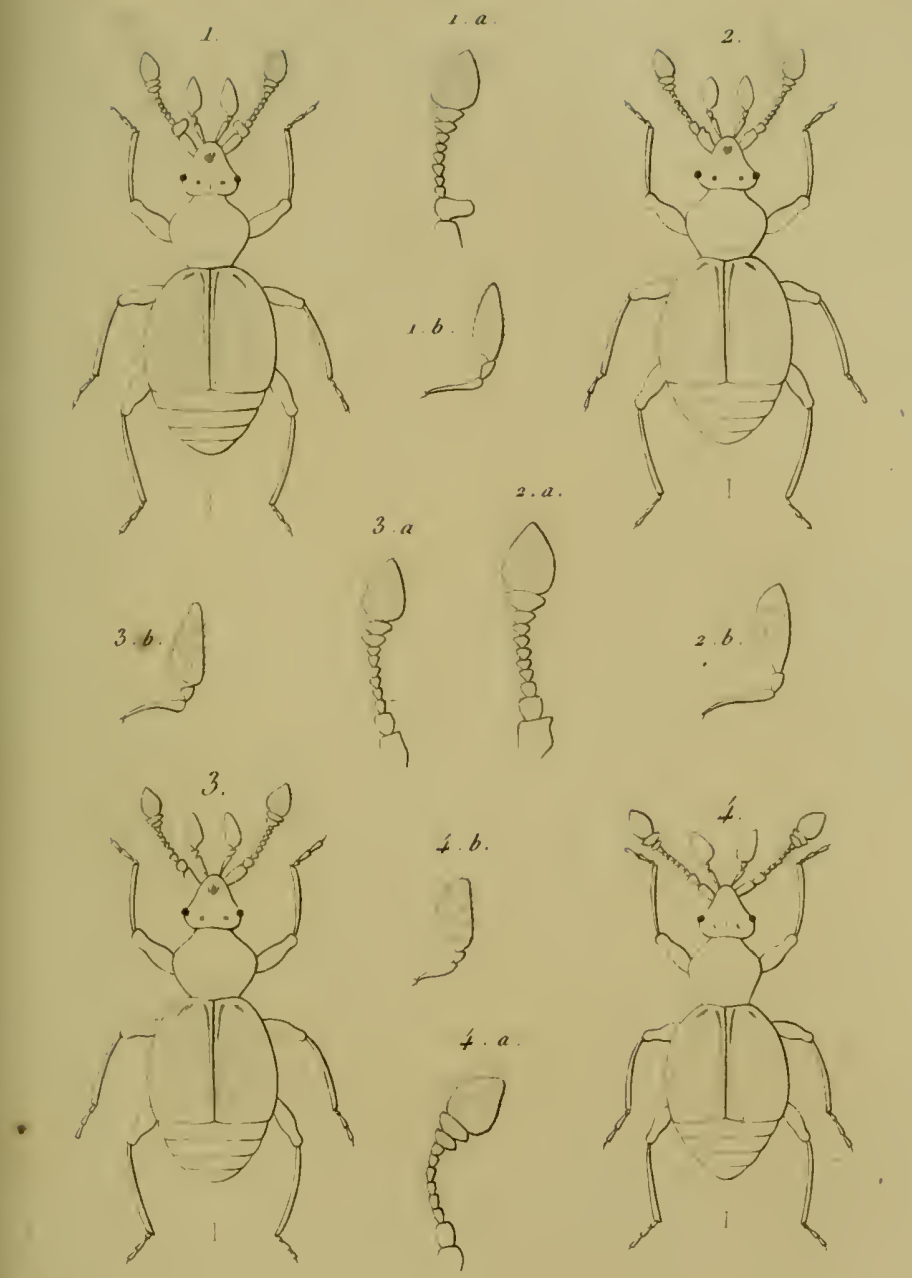


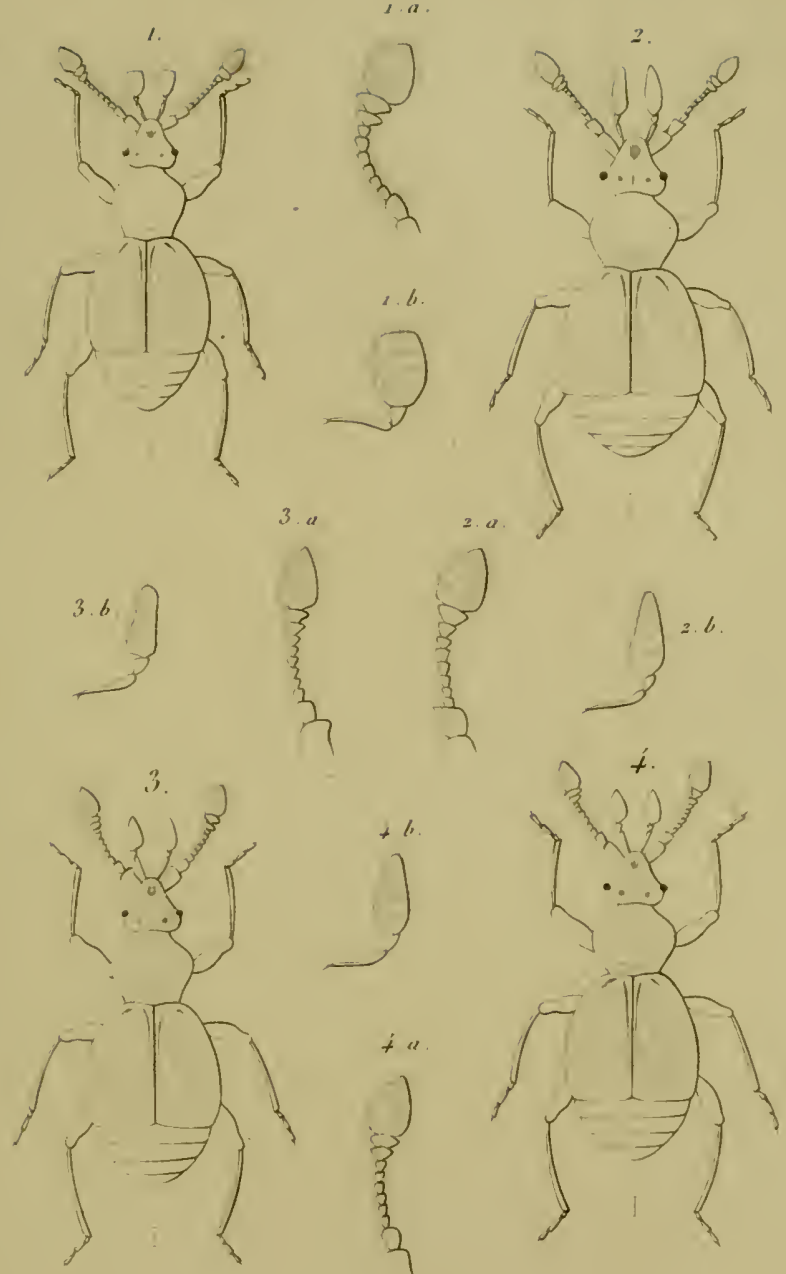

\section{Bithinus}
1. B. ylobulipalpus subé.
2. B. clavicornis Pun
3. B. Chevroluiti subi
4. B. punclicollis. Denny. 



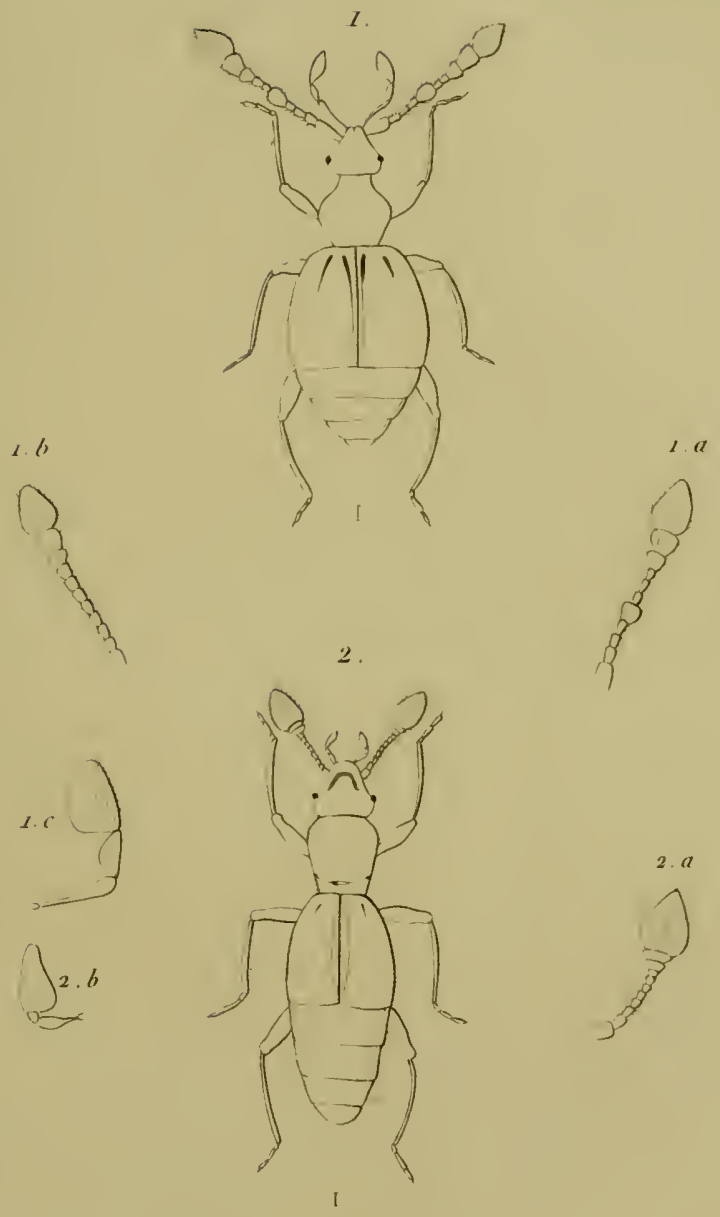

1. Tychus niger. Payk. 2. Trimium brenicorne. Reush. 


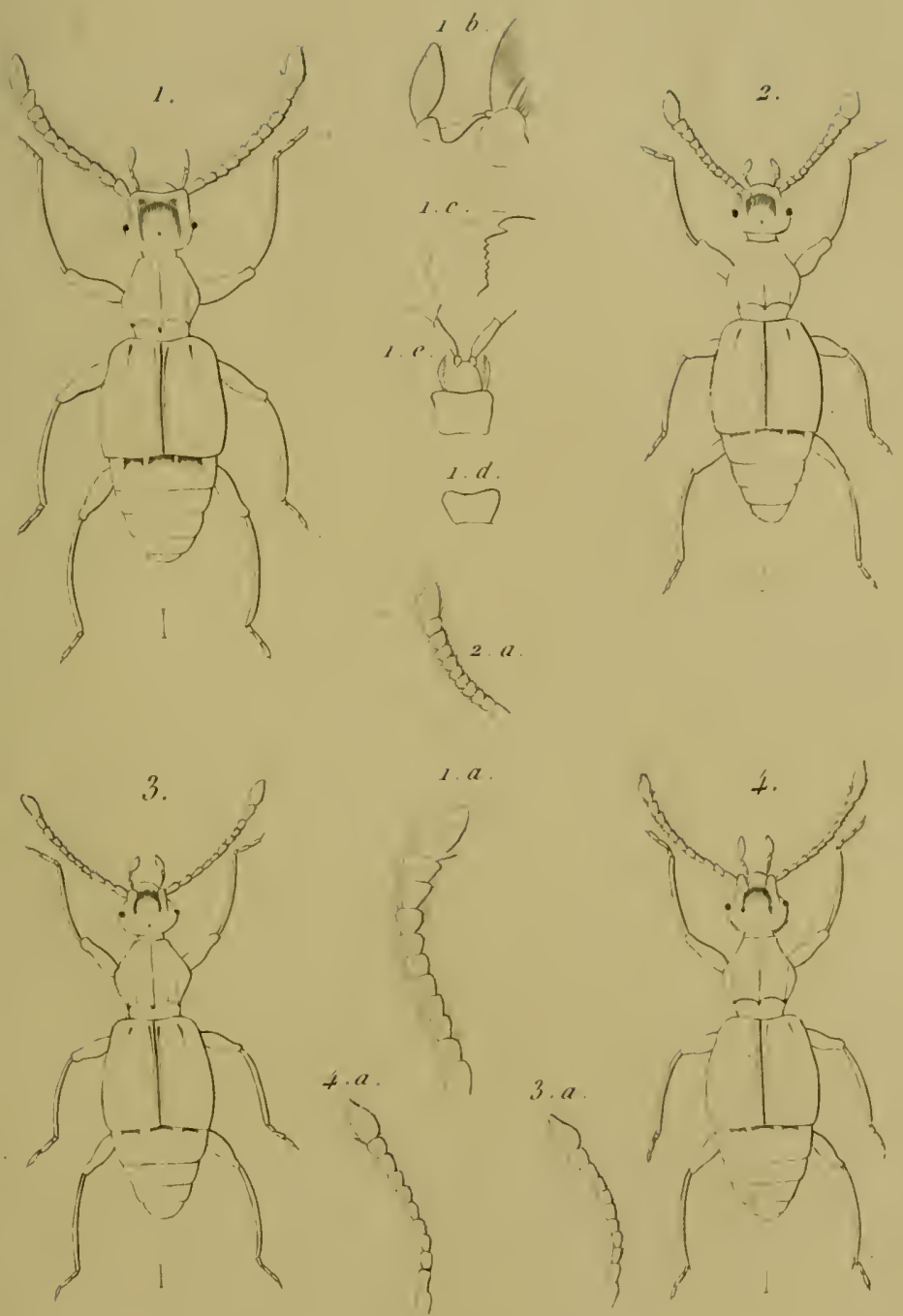

Batrisus
1. B. formicariue - lube
2. B. Diduporti - Lubses.
3. B. Brullei stubir .
+13 ocelalues 7$)$ 


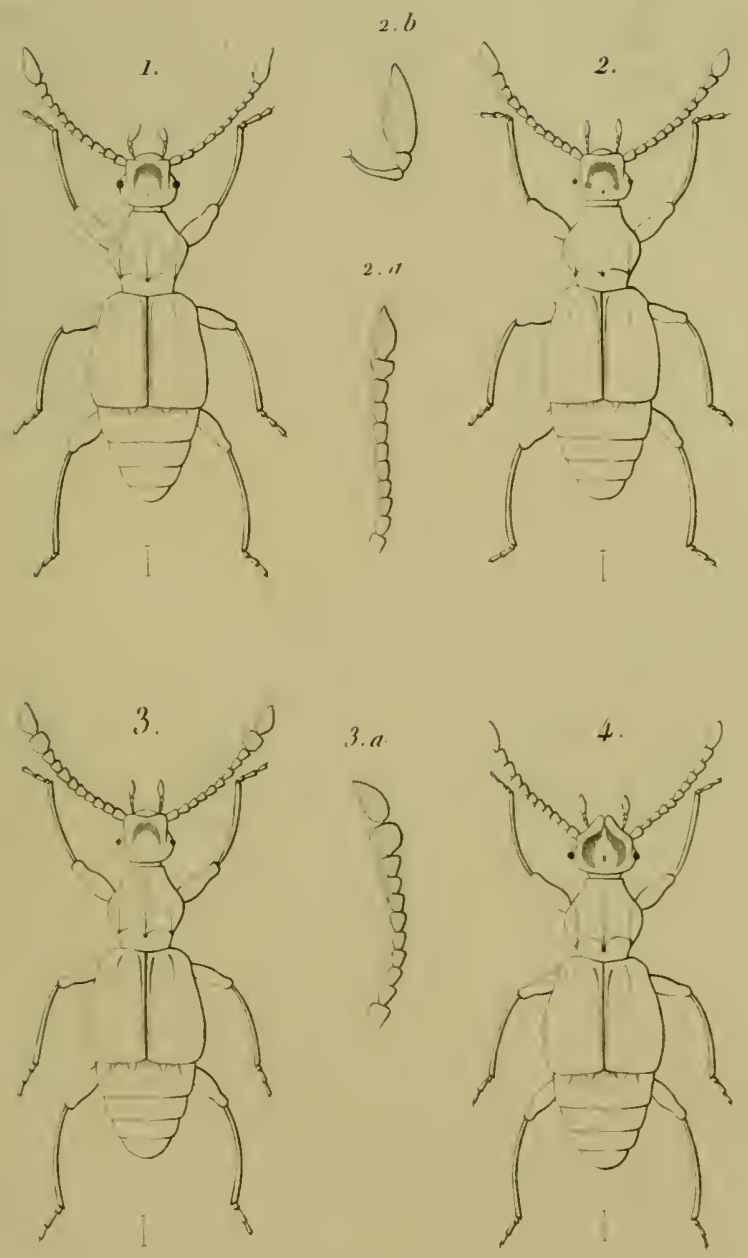

\section{Batrisus}
1. B. uenushus. Reich.
2. B. albionieus. Digi.
3. B. Linenticollis. Dej.
4. B. Buqueli. Aube . 


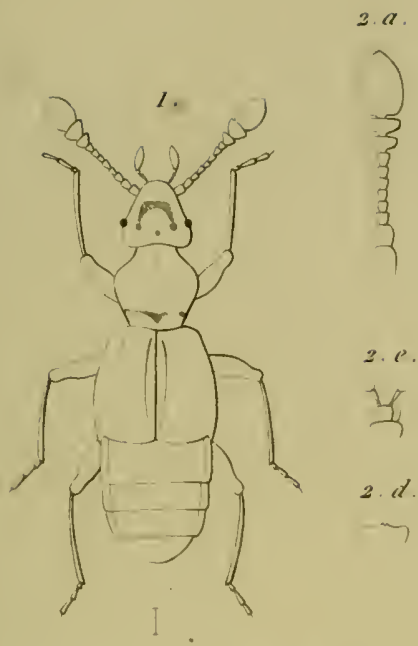

$$
\text { 2.c. }
$$
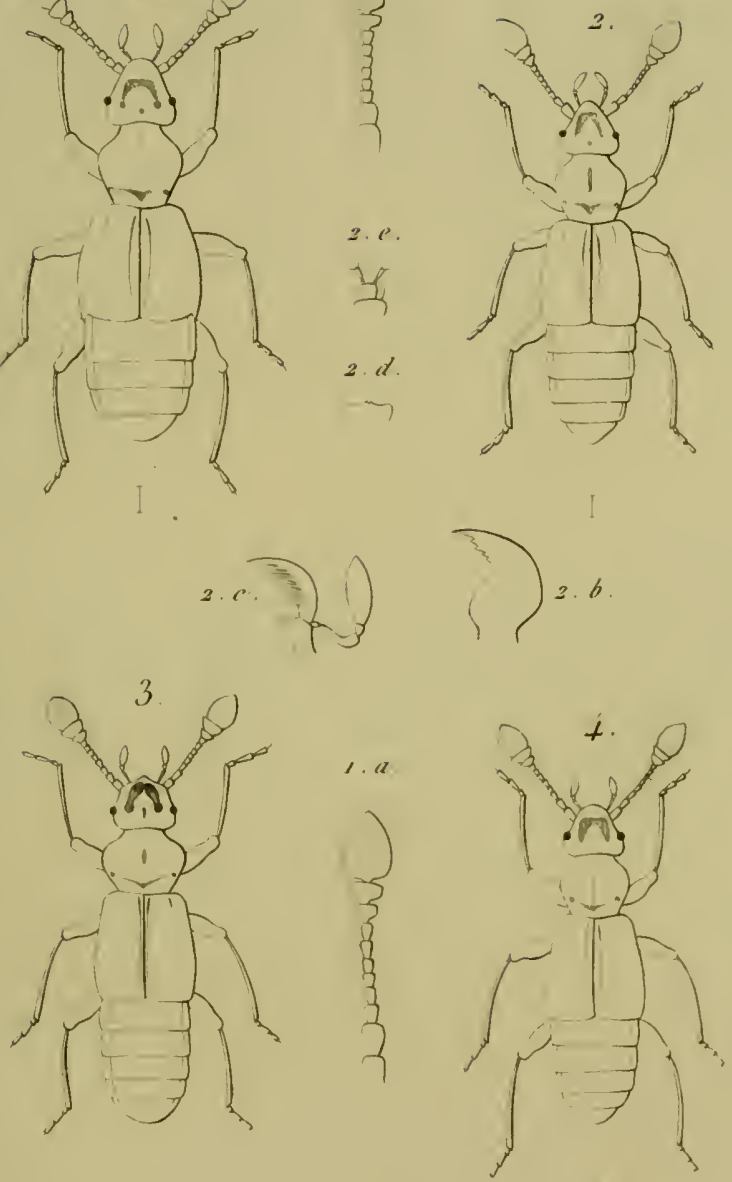

\section{Finplecus}
1. H. suticicollis . Rewh.
2. Fi. nanus. Reach.
3. E. Fischeri $x \times$
+. F. Kirbii . Menmy. 


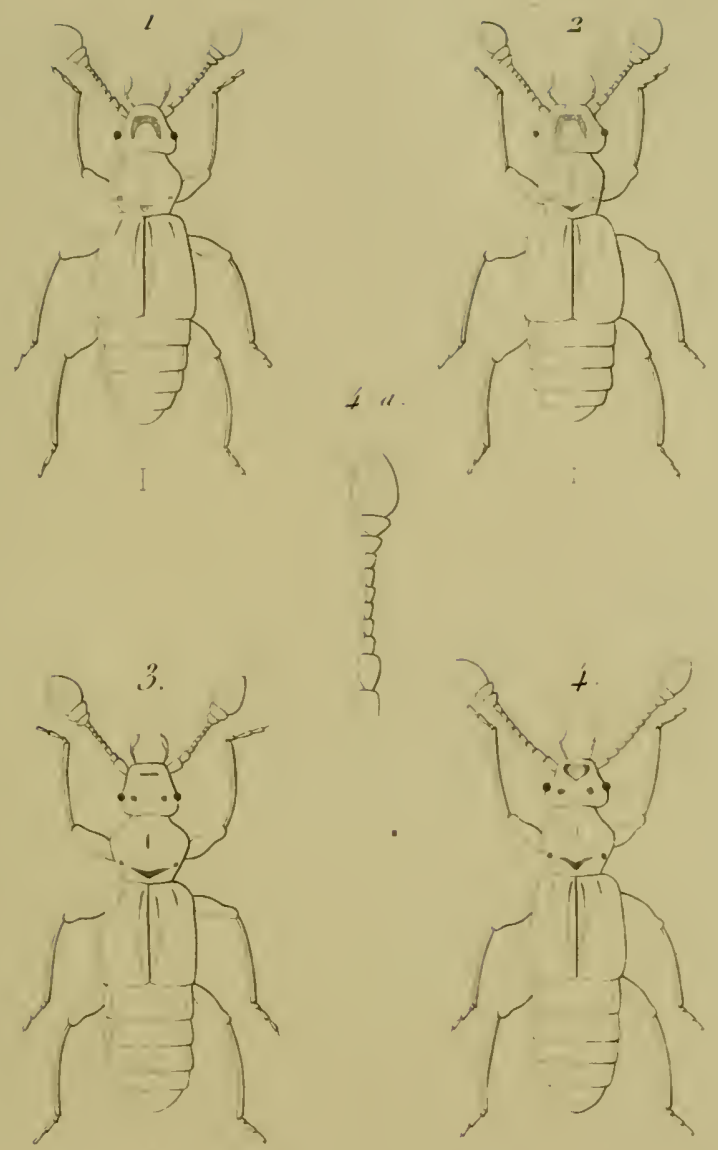

\section{linplectus}
1. 1‥ sangurinems. Denmy.

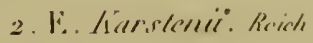
3. L. signallur. Rasich. +. E. Mnponsie. Aubé 


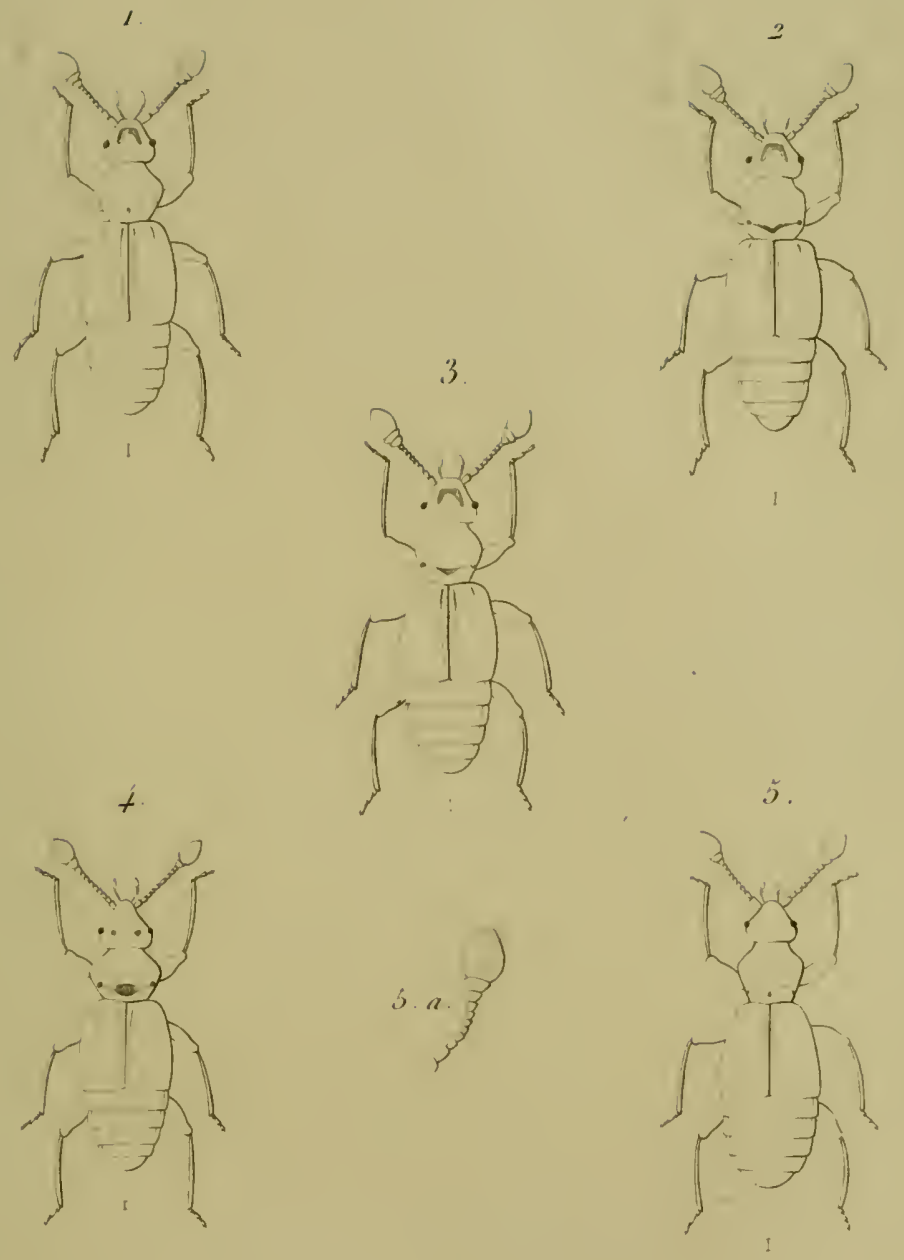

Tiuplectus

1.1. bicolor. Denny 2.E. ambiguus. Reirh 3. R. pusallus. Denny.

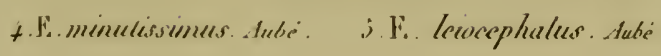




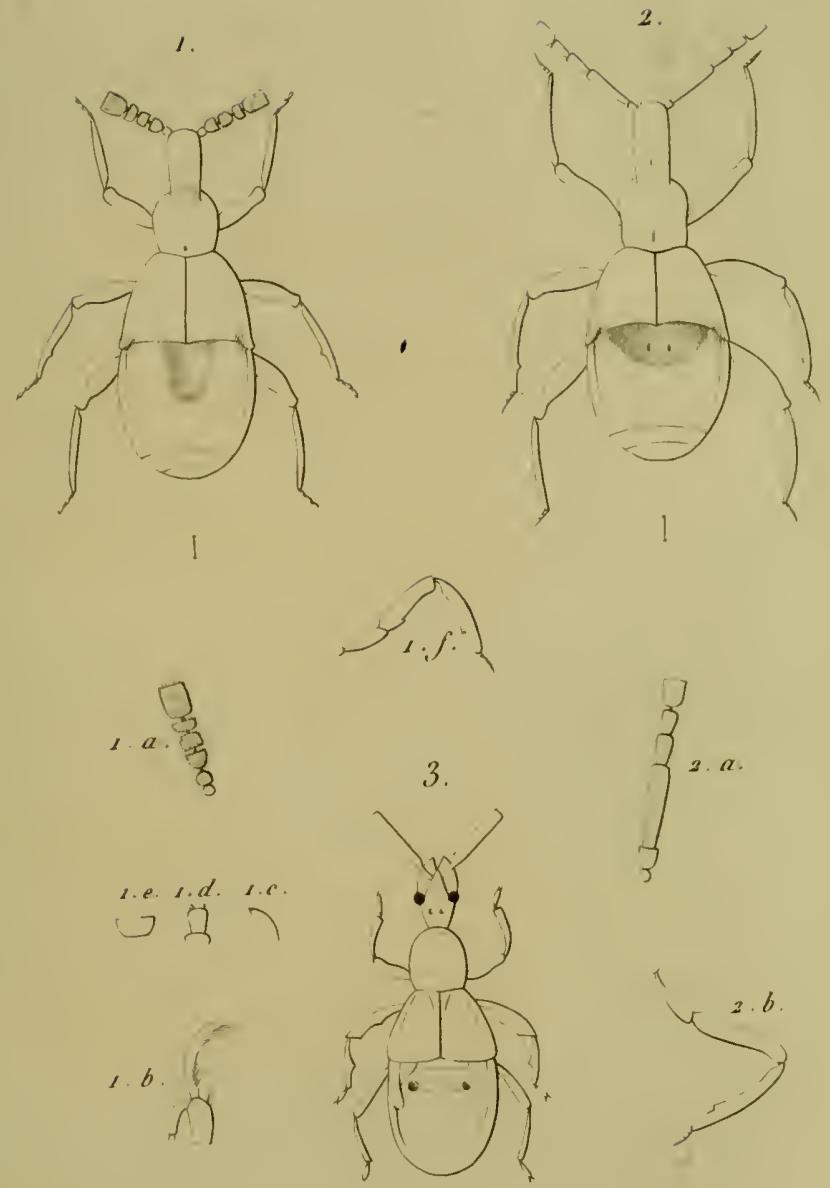

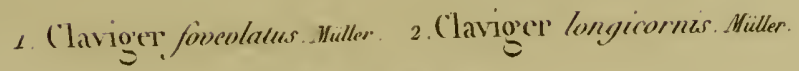
3. Arlicerus armatus. Dalmun . 






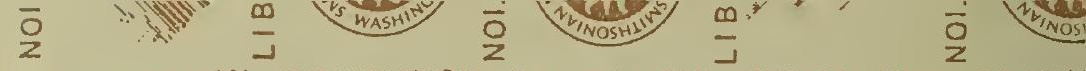

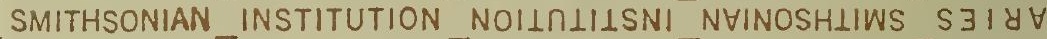

$\frac{z}{0}$
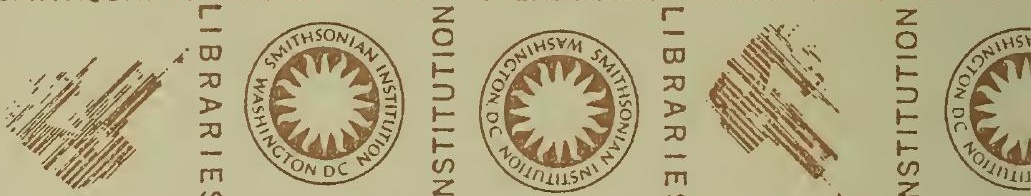

NHINOSH1IWS

S $314 \forall y 817$
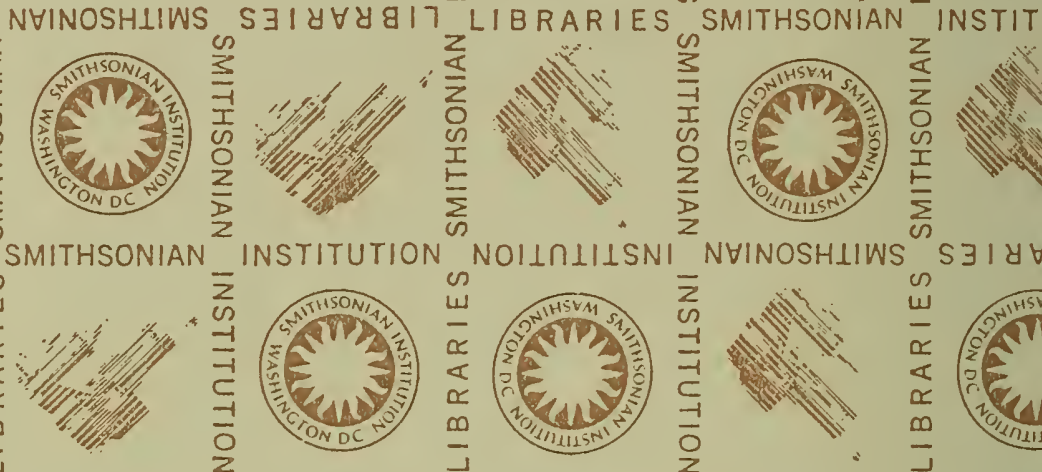

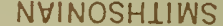

$5 \exists 18 b$

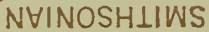
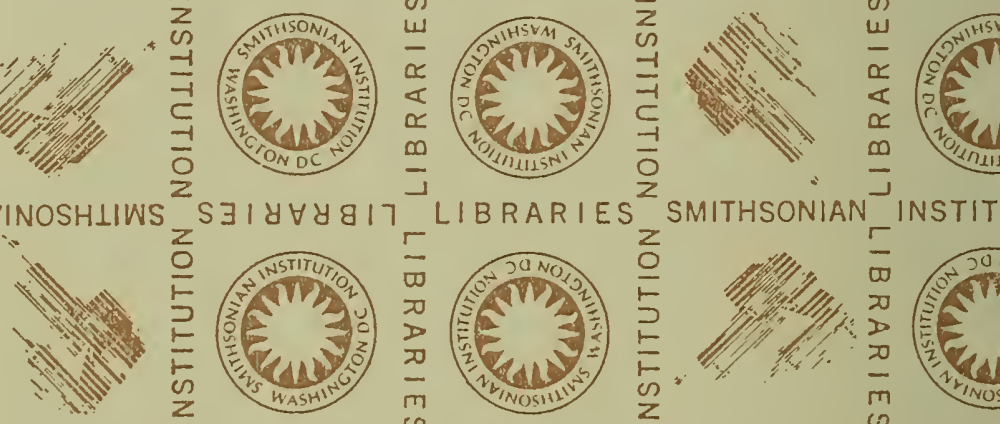

SMITHSONIAN
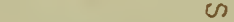

LIBRARIES

SMITHSONIAN

INSTIT
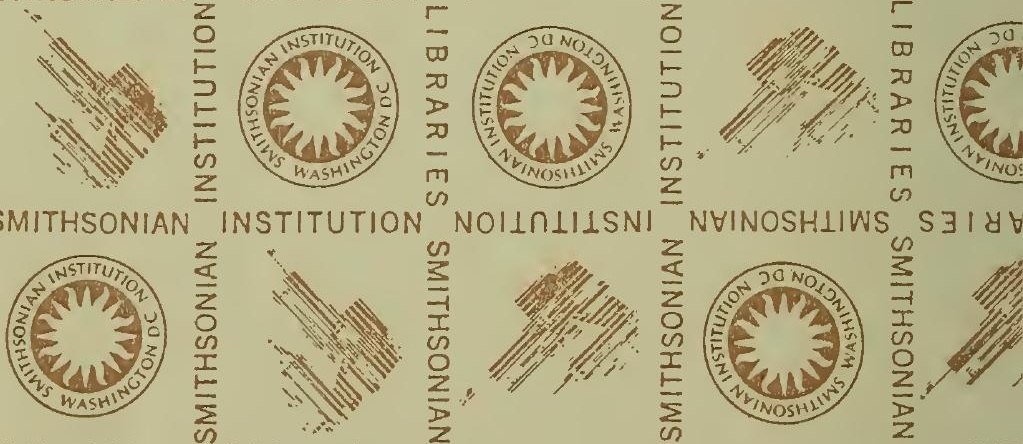

NHINOSHIIWS

$\bar{z}$
n
-1
$\bar{z}$
$\bar{y}$
$\overline{0}$
$z$
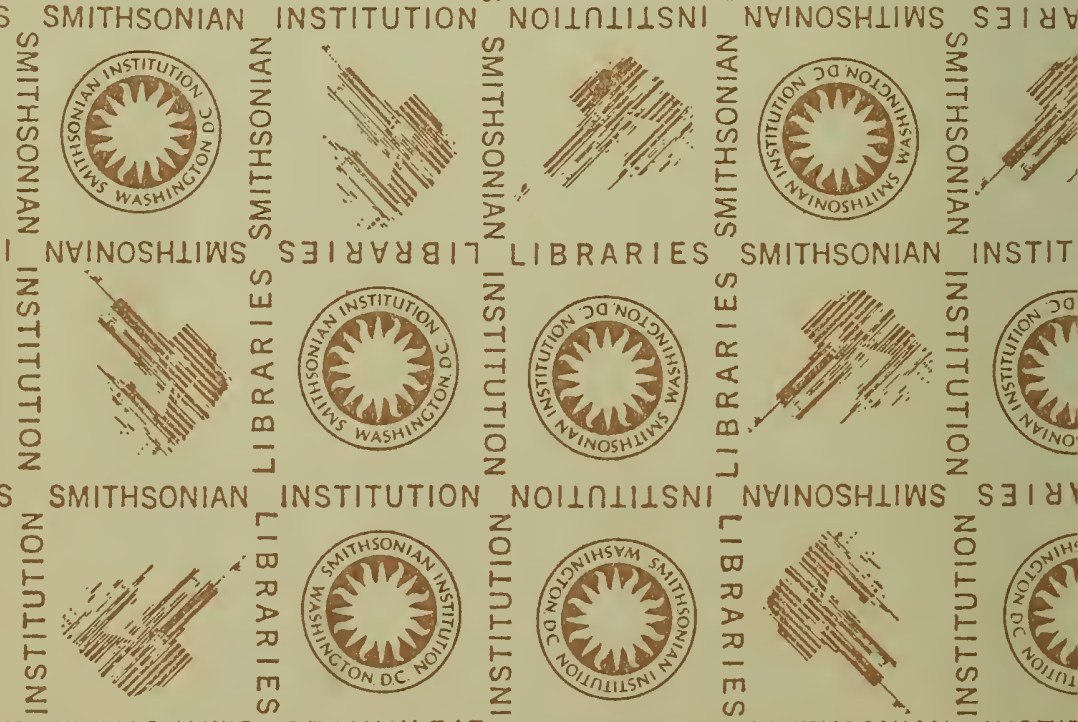

NYINOSHLIWS S $\exists I Y$

NI

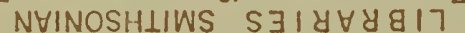

$\frac{z}{z}$

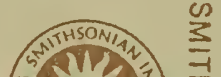

$\frac{z}{z}$
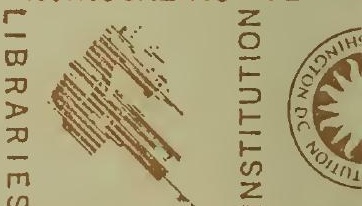

a $z$ z

INSTI

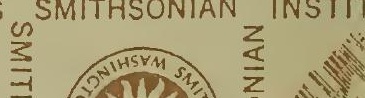


